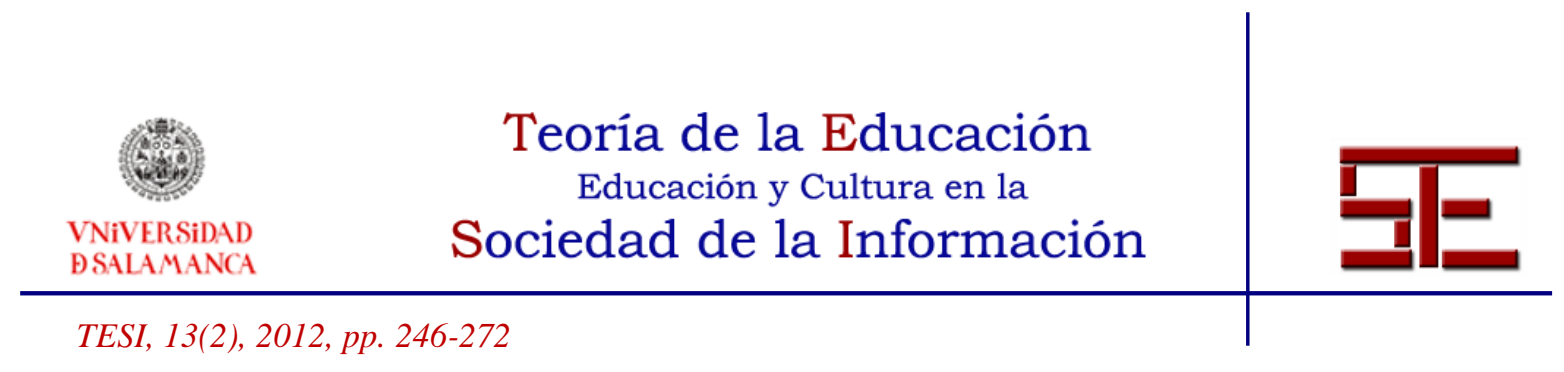

\title{
UN APRENDIZ ESTRATÉGICO PARA UNA NUEVA SOCIEDAD
}

Resumen: Nuevos tiempos precisan de nuevos aprendices. En una escuela inmersa en la sociedad de la información, que queremos que sea del conocimiento, hace falta desarrollar nuevas actitudes y habilidades para el aprendizaje. El estudiante ha de aprender a desarrollar su autonomía y responsabilidad en un mundo abierto en que hay sobreabundancia de información y estímulos. Para ello hace falta que el estudiante llegue a ser "aprendiz estratégico", una persona autónoma que quiere aprender para crecer, para sí y para los demás, teniendo como referente los valores, alguien que aprende a movilizar, observar, evaluar, planificar y controlar sus propios procesos de aprendizaje. Estamos hablando de aprendizaje autorregulado, de "aprender a aprender". Y, si bien es cierto que la escuela ha perdido su papel clave en la transmisión de la información, también lo es que se constituye en el espacio privilegiado para enseñar a aprender a aprender. La autorregulación, el pensamiento crítico, el compromiso cívico, etc., han de asentarse en la escuela para continuar creciendo luego, y se pueden y deben trabajar desde edades tempranas. En este trabajo presentamos claves para el desarrollo del aprendizaje estratégico en el sistema educativo.

Palabras clave: Aprendizaje estratégico; aprendizaje autorregulado; aprender a aprender; sociedad del conocimiento.

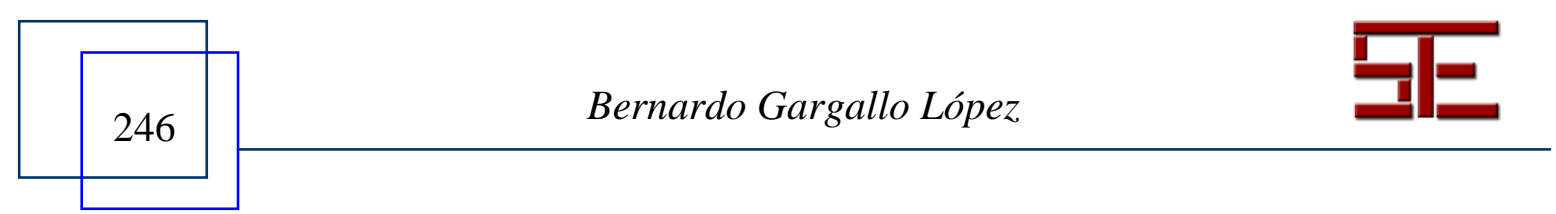




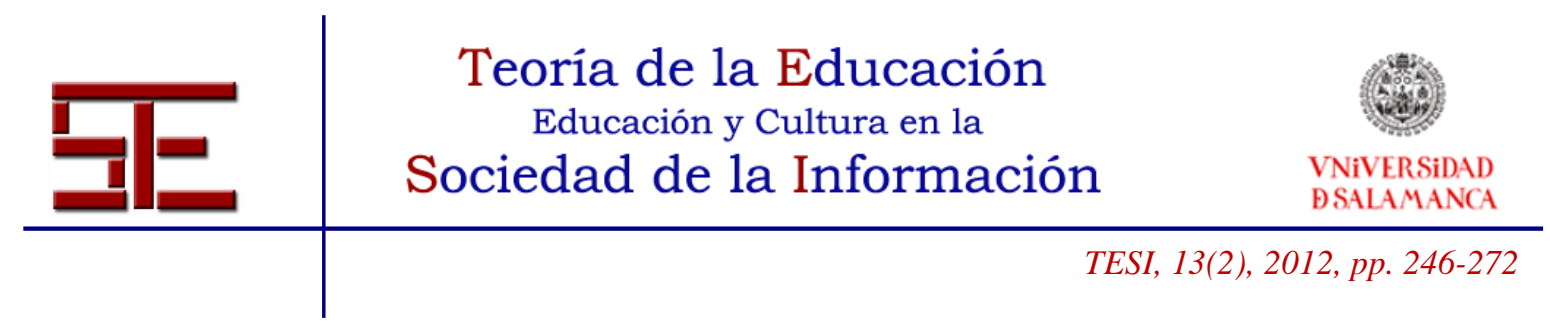

\title{
A STRATEGIC LEARNER FOR A NEW SOCIETY
}

\begin{abstract}
New times require new learners. Developing new attitudes and skills for learning is necessary in a school immersed in the information society, which we want to become the knowledge society. The students must learn to develop their autonomy and responsibility in an open world where there are a lot of information and stimuli. In this context, it's necessary the student to become a "strategic learner", an autonomous person who wants to learn to grow for himself and for other people, with reference to values; someone who learns to mobilize, observe, assess, plan and control their own learning processes. We're talking about self-regulated learning, about "learning to learn". And, although it's true that the school has lost its key role in the transmission of information, it is also true that the school becomes a privileged place to teach learning to learn. The self-regulation, the critical thinking, the civic commitment, etc. have to settle in the school to continue growing, and they can be taught and must be taught from an early age. In this work we enclose some clues for the development of strategic learning in the educational system.
\end{abstract}

Keywords: Strategic learning; self-regulated learning; learning to learn; knowledge society.

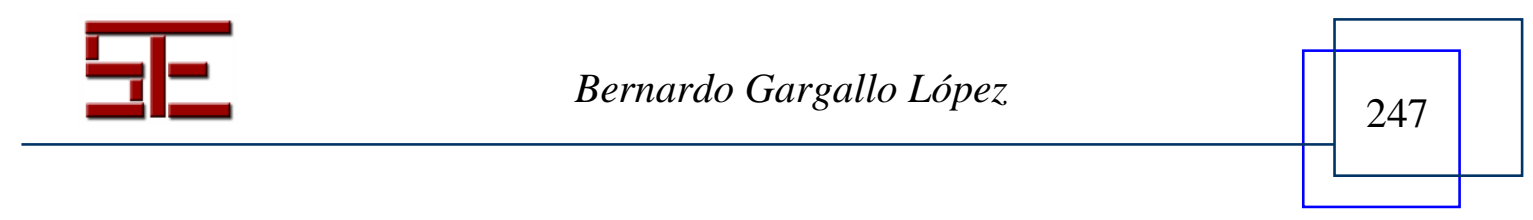




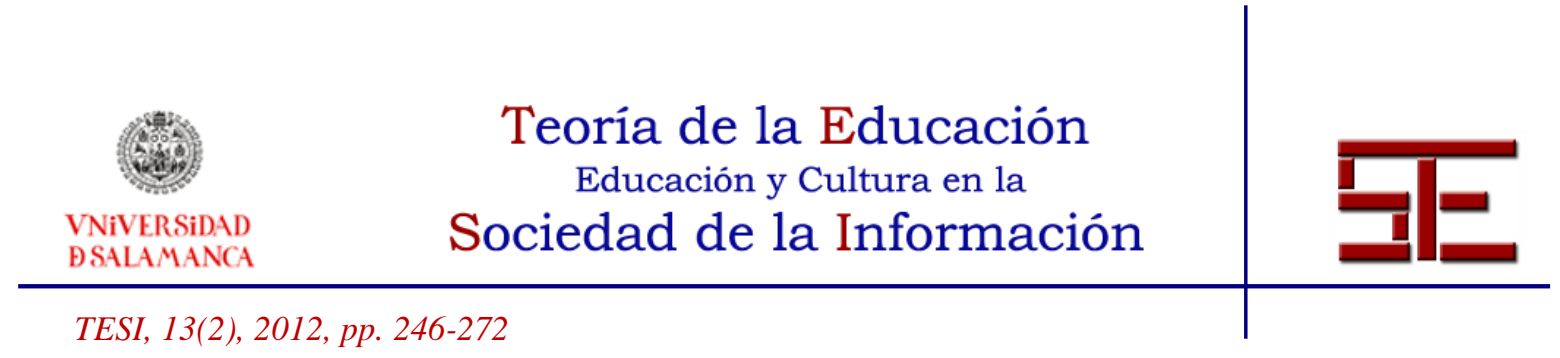

UN APRENDIZ ESTRATÉGICO PARA UNA NUEVA SOCIEDAD

Fecha de recepción: 20/09/2011; fecha de aceptación: 20/10/2011; fecha de publicación: 26/07/2012

Bernardo Gargallo López

bernardo.gargallo@uv.es

Universidad de Valencia

\section{1.- INTRODUCCIÓN}

Estamos inmersos en la sociedad de la información, que no del conocimiento. La sociedad del conocimiento es el objetivo. Sociedad de la información implica disponer de información y esto sí es un hecho en nuestros tiempos. En un par de generaciones el salto ha sido cuantitativa y cualitativamente excepcional. Los medios de comunicación de masas e Internet especialmente lo han cambiado todo. Hoy los niños, los jóvenes y los adultos disponen de sobreabundancia de información. Información que se filtra y selecciona, en gran medida, en función de intereses diversos, a veces nada recomendables. Así y todo, es difícil "poner fronteras al campo". Lo ocurrido en los países del Magreb en la primavera de 2011, que quedará para la historia, es un ejemplo de ello. Es cierto que el mundo se ha hecho pequeño y uno puede asomarse a lo que ocurre en la parte más lejana de modo inmediato. Siendo conscientes de que sigue existiendo la brecha digital y de que hay zonas mucho más desconectadas que otras.

El impacto de las TIC y la globalización que las acompaña han comportado modificaciones drásticas. Son tan grandes los cambios en la ciencia, en la tecnología y en la dinámica de los pueblos que la necesidad de formación permanente se ha hecho, si cabe, todavía más acuciante. Hay disciplinas científicas en que el conocimiento disponible se duplica cada año. Por eso, un profesional competente necesita continuar aprendiendo y aprendiendo mucho. Los acelerados cambios que vivimos obligan al reciclaje y a la formación permanente. No es casualidad que el concepto de educación se solape hoy en día con el de educación permanente.

Disponemos, pues, de mucha información en nuestros días. Sin embargo, no basta con disponer de información para hablar de conocimiento, ni para hablar de sociedad del conocimiento. La construcción de conocimiento requiere dar algunos pasos más: significa seleccionar la información adecuada de entre la mucha disponible, atender a diversas fuentes para comparar siendo conscientes de la posibilidad de sesgos

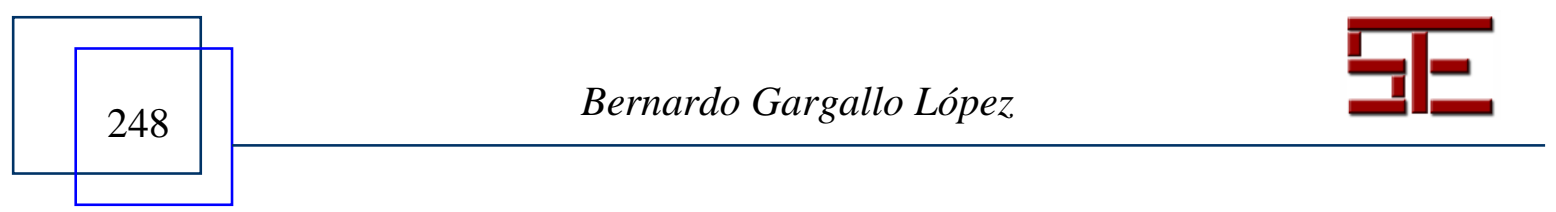




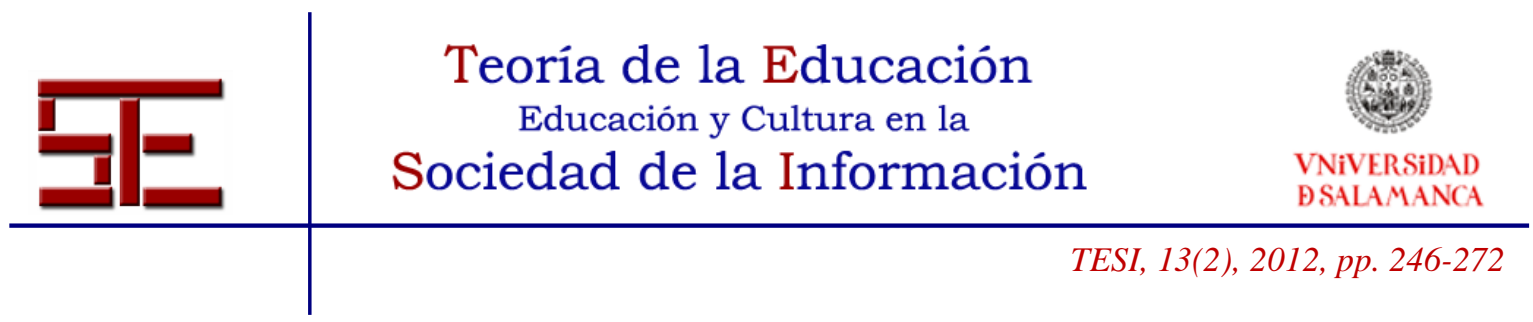

ideológicos y/o de intereses existentes en las diversas fuentes, discernir, analizar a fondo la información, valorarla críticamente, integrarla de modo significativo en las estructuras cognitivas haciéndola propia, y utilizarla eficazmente para la vida. El conocimiento es mucho más que información. La información es la materia prima para construir conocimiento, pero éste requiere un esfuerzo añadido.

En este contexto, el del esfuerzo por construir la sociedad del conocimiento, a partir de la información disponible, cobra una importancia fundamental la necesidad de "aprender a aprender", uno de los principios clave de la educación actual y una tarea esencial a desarrollar en el sistema educativo reglado. En un mundo complejo y cambiante como el nuestro en que la información crece de una manera exponencial es impensable que nuestros alumnos puedan aprender en esa escuela todos los conocimientos que necesitarán en su vida futura, porque un ciudadano consciente y un profesional competente siempre necesitarán seguir aprendiendo. Es, por lo tanto, preciso desarrollar habilidades para manejarse con la información, de cara a transformarla en conocimiento. Desde nuestro punto de vista, tan importante como aprender contenidos conceptuales fundamentales, o más si cabe, lo es aprender procedimientos y estrategias para manejar la información, que permitirán al aprendiz y al profesional continuar aprendiendo a lo largo de la vida. En eso consiste el aprender a aprender, en aprender estrategias de aprendizaje, en aprender de modo autorregulado.

Pero no se trataría de un planteamiento puramente instrumental o tecnocrático, de manejo de "herramientas" sin cuestionarse los fines, sino de una orientación ligada a valores y al logro de la autonomía y responsabilidad, eje fundamental del Congreso DE Teoría de la Educación. En los apartados que siguen desarrollamos estas ideas.

\section{2.- LAS HERRAMIENTAS PARA APRENDER. APRENDIZAJE AUTORREGULADO/APRENDIZAJE ESTRATÉGICO}

Desde nuestro punto de vista, cuando estamos hablando de aprendizaje autorregulado estamos hablando de aprendizaje estratégico, un concepto claramente ligado a la autonomía, y también a la responsabilidad. Y ello es así porque el aprendiz estratégico gana en autonomía y también en responsabilidad. Aprender estratégicamente supone funcionamiento autónomo y también implica desarrollar la responsabilidad.

Las estrategias de aprendizaje son un constructo multidimensional, polisémico y confuso en ocasiones, del que se han dado múltiples definiciones (Ayala; Martínez y

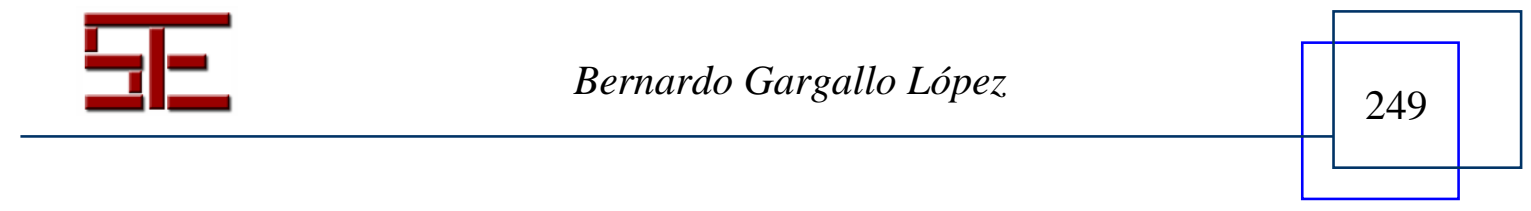




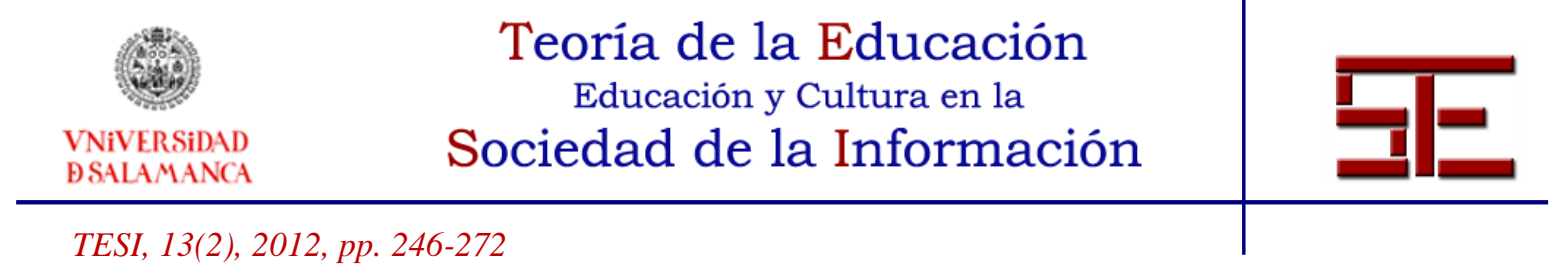

Yuste, 2004; Beltrán, 2003; Bernad, 1999; Danserau, 1985; Kirby, 1984; Monereo, 1997; Nisbet y Shucksmith, 1987; Pozo, 1990; Weinstein y Danserau, 1985).

Cuando hablamos de estrategias de aprendizaje, de aprendizaje estratégico, estamos hablando de voluntad, de intencionalidad, de conciencia de metas, de control de la actividad cognitiva por parte del aprendiz, de valoración de caminos alternativos y de toma de decisiones ajustadas a las condiciones del contexto, que permiten movilizar las habilidades necesarias para un aprendizaje exitoso en una situación determinada. Como puede verse, son todos ellos elementos vinculados a la autonomía. Actuar estratégicamente supone querer aprender eficazmente y diseñar y ejecutar planes de acción ajustados a las metas previstas y a las condiciones del contexto, seleccionando y poniendo en marcha procedimientos, habilidades y técnicas eficaces para aprender (García y Pintrich, 1993) cuya efectividad ha de evaluarse para modificar lo que se precise. Las estrategias de aprendizaje integran elementos afectivo-motivacionales y de apoyo ("querer", lo que supone disposiciones y clima adecuado para aprender), metacognitivos ("tomar decisiones y evaluarlas", lo que implica la autorregulación del alumno) y cognitivos ("poder", lo que comporta el manejo de estrategias, habilidades y técnicas relacionadas con el procesamiento de la información) (Ayala, Martínez y Yuste, 2004; Corno, 1994; García y Pintrich, 1991; Gargallo, 2000).

Desde esta concepción amplia de las estrategias de aprendizaje nos encontramos en el contexto del aprendizaje autorregulado, como decíamos más arriba. Un aprendiz estratégico es un aprendiz autorregulado. No puede ser de otra manera. Vamos a verlo a continuación.

El aprendizaje autorregulado es también un constructo complejo que implica aspectos cognitivos, metacognitivos, motivacionales y contextuales (Zimmerman, 1990). Se puede entender como el grado en que los individuos se muestran participantes activos a nivel cognitivo, motivacional y conductual de su propio proceso de aprendizaje (Zimmerman y Martínez Pons, 1988). El aprendizaje autorregulado incluye la "metacognición" como un elemento básico (Abascal, 2003). De hecho, el desarrollo de habilidades metacognitivas para planificar, supervisar, regular y evaluar el aprendizaje es fundamental de cara a que se dé aprendizaje autorregulado. Sin embargo, la autorregulación es más amplia e incluye otros procesos y elementos, no sólo los cognitivos y metacognitivos, sino también los motivacionales y afectivos, comprendiendo el autocontrol de la cognición, la motivación, el afecto y la conducta (Pintrich, 1995). Es ésta la perspectiva que suscribimos del concepto, una perspectiva

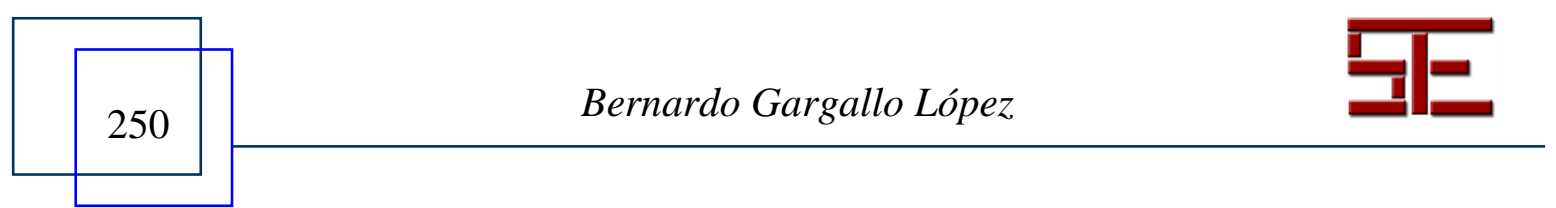




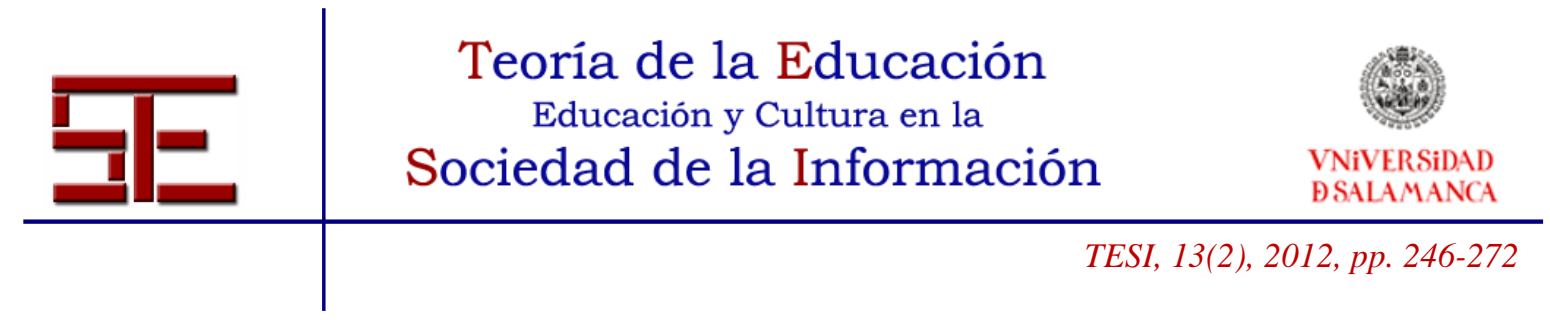

más integradora que sintoniza perfectamente con el concepto amplio de estrategias de aprendizaje que hemos presentado.

El aprendizaje autorregulado, el aprendizaje estratégico, también se aprende. Por eso se habla de "aprender a aprender". Y se puede enseñar. En ese empeño, en el de ayudar a los estudiantes a aprender estratégicamente, o de modo autorregulado, es fundamental articular una adecuada estructura teórica, un "mapa" lo más completo posible que integre las diversas estrategias que se movilizan para aprender sin dejar fuera elementos sustantivos, que podamos utilizar como referente teórico para decidir qué estrategias enseñar, antes de afrontar el modo de enseñarlas.

Con esa pretensión de globalidad, hemos articulado una propuesta propia que se concreta en la clasificación de estrategias que se recoge a continuación, que es coherente con las aportaciones de otros expertos (Beltrán, 2003; Bernad, 1999; Gargallo, 1995; Justicia y Cano, 1993; Pozo, 1990; Román y Gallego, 1994; Pintrich, Smith, García y Mckeachie, 1991; Weinstein, Palmer y Schulte, 1987), a las que completa (Tabla 1):

Tabla 1. Clasificación de estrategias de aprendizaje

\begin{tabular}{|c|c|c|}
\hline \multirow{2}{*}{$\begin{array}{l}\text { Estrategias afectivas, } \\
\text { disposicionales y } \\
\text { de apoyo }\end{array}$} & \multicolumn{2}{|c|}{ 1. Estrategias afectivo-emotivas y motivacionales } \\
\hline & \multicolumn{2}{|c|}{$\begin{array}{l}\text { 2. Estrategias de control del contexto, interacción social y manejo de } \\
\text { recursos }\end{array}$} \\
\hline \multirow{3}{*}{$\begin{array}{l}\text { Estrategias metacognitivas, de } \\
\text { regulación y control }\end{array}$} & \multicolumn{2}{|c|}{ 1. Conocimiento } \\
\hline & \multirow[t]{2}{*}{ 2. Control } & 2.1. Estrategias de planificación \\
\hline & & $\begin{array}{l}\text { 2.2. Estrategias de evaluación, control y } \\
\text { regulación }\end{array}$ \\
\hline \multicolumn{3}{|c|}{ Estrategias de búsqueda, recogida y selección de información } \\
\hline \multirow{6}{*}{$\begin{array}{l}\text { Estrategias de procesamiento } \\
\text { y uso de la información }\end{array}$} & \multicolumn{2}{|c|}{ 1. Estrategias de adquisición de información } \\
\hline & \multicolumn{2}{|c|}{$\begin{array}{l}\text { 2. Estrategias de codificación, elaboración y organización de la } \\
\text { información }\end{array}$} \\
\hline & \multicolumn{2}{|c|}{ 3. Estrategias de personalización y creatividad } \\
\hline & \multicolumn{2}{|c|}{ 4. Estrategias de repetición y almacenamiento } \\
\hline & \multicolumn{2}{|c|}{.5. Estrategias de recuperación de la información } \\
\hline & \multicolumn{2}{|c|}{$\begin{array}{l}\text { 6. Estrategias de comunicación, uso de la información adquirida y } \\
\text { transferencia }\end{array}$} \\
\hline
\end{tabular}

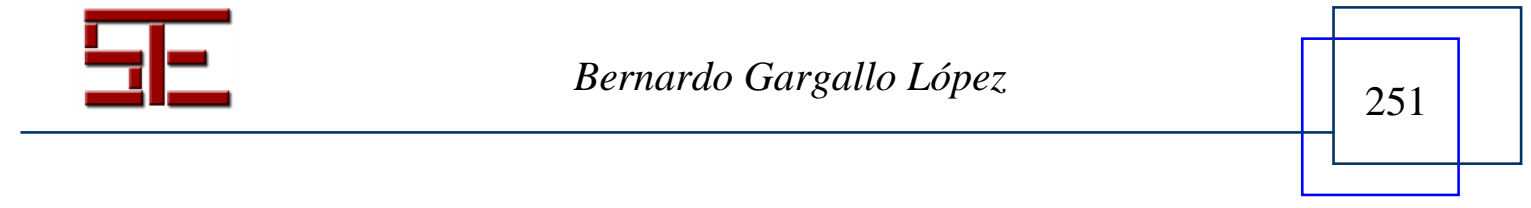




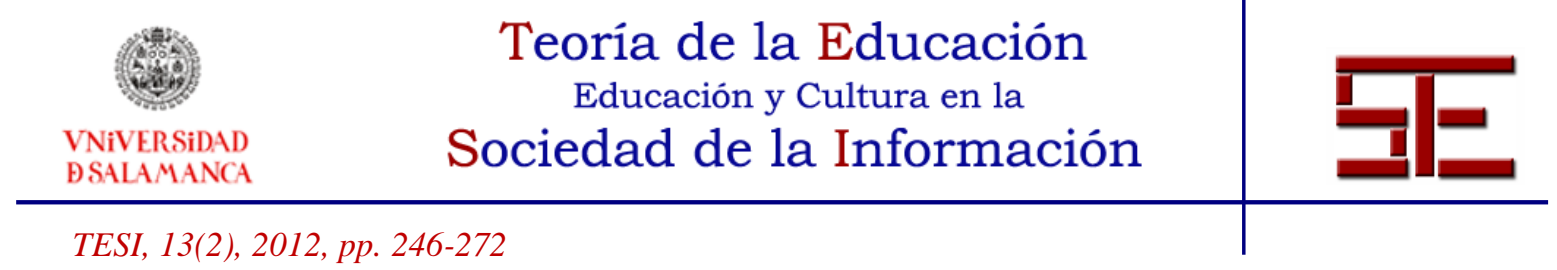

La explicitación de la misma es la que sigue:

1. Estrategias afectivas, disposicionales y de apoyo. Estas estrategias se asocian con el "querer", con la gestión de las disposiciones, de la motivación y del clima adecuado para aprender; son las que ponen la marcha el proceso y ayudan a sostener el esfuerzo. Aquí se incluyen dos tipos de estrategias:

1.1. Estrategias afectivo-emotivas y motivacionales: que integran procesos motivacionales, actitudes adecuadas, autoconcepto-autoestima, autoeficacia, sentimiento de competencia, relajación, control de la ansiedad, reducción del estrés, etc.

1.2. Estrategias de control del contexto, interacción social y manejo de recursos: se refieren a la creación de condiciones ambientales adecuadas, control del espacio, del tiempo, del material, relaciones interpersonales pertinentes, etc.

2. Estrategias metacognitivas, de regulación y control: se refieren al conocimiento, evaluación y control de las diversas estrategias y procesos cognitivos, de acuerdo con los objetivos de la tarea y en función del contexto. Están relacionadas con la "toma de decisiones y con su evaluación", con la autorregulación del alumno. Integran:

2.1. Conocimiento: se refieren al conocimiento de la propia persona, de las estrategias disponibles, de las destrezas y limitaciones, de los objetivos de la tarea y del contexto de aplicación.

2.2. Control: integran todo lo referido al control que el aprendiz puede ejecutar sobre sus propios procesos de aprendizaje. Pueden ser:

exámenes, etc.

2.2.1. Estrategias de planificación: del trabajo, estudio,

2.2.2. Estrategias de evaluación, control y regulación: implican verificación y valoración del propio desempeño, control de la tarea, corrección de errores y distracciones, rectificaciones, autorrefuerzo, etc.

3. Estrategias de búsqueda, recogida y selección de información: integran todo lo referente a la localización, recogida y selección de información. El estudiante debe aprender, para ser aprendiz estratégico, cuáles son las fuentes de información y cómo acceder a ellas para disponer de la misma. Debe aprender, también, mecanismos y criterios para seleccionar la información pertinente. Tanto éstas como las que siguen son estrategias relacionadas con el "poder", con el manejo de habilidades relacionadas con el procesamiento de la información.

4. Estrategias de procesamiento y uso de la información adquirida: son las dirigidas al trabajo sobre los materiales para su comprensión, integración y uso eficaz. Incluyen:

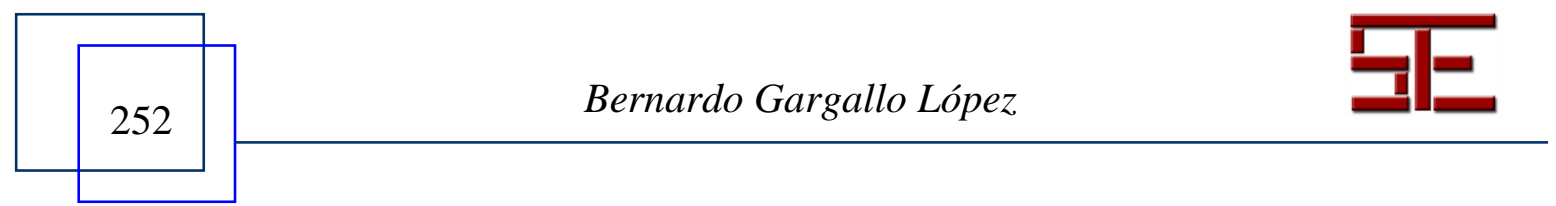




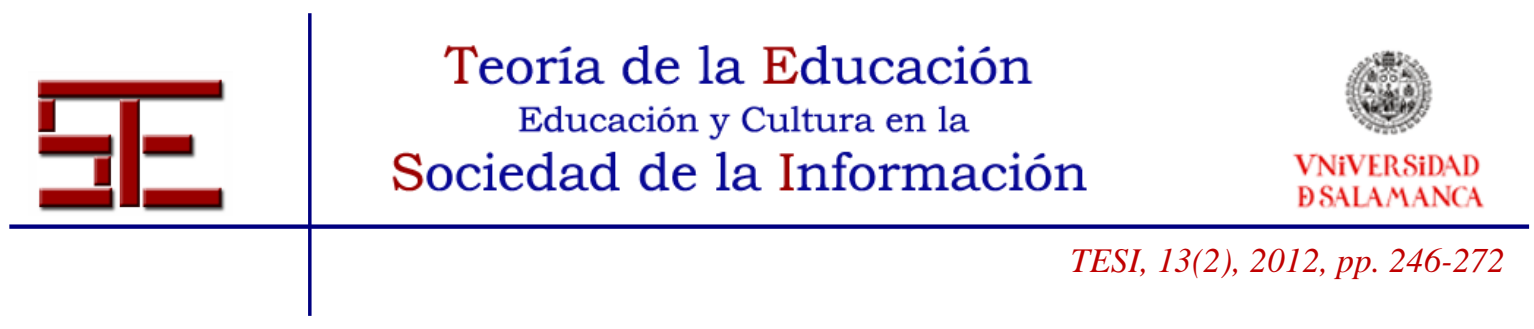

4.1. Estrategias de adquisición de información: suponen atender a los profesores, a aspectos fundamentales de los contenidos, manejo de técnicas como la toma de notas y apuntes, la prelectura, la lectura comprensiva, etc.

4.2. Estrategias de codificación, elaboración y organización de la información: controlan los procesos de reestructuración, elaboración y organización de la información para hacerla propia, de cara a integrarla mejor en la estructura cognitiva, a través de técnicas como el subrayado, el epigrafiado, el resumen, los esquemas, los mapas conceptuales, etc.

4.3. Estrategias de personalización y creatividad: incluyen el pensamiento crítico, las propuestas personales creativas, etc.

4.4. Estrategias de repetición y almacenamiento: que controlan los procesos de retención y memoria a corto y largo plazo, a través de técnicas como la copia, la repetición, los recursos mnemotécnicos, el establecimiento de conexiones significativas, etc.

4.5. Estrategias de recuperación de la información: que controlan los procesos de recuerdo y recuperación, a través de técnicas como los ejercicios de recuerdo, los de recuperación de la información siguiendo la ruta de conceptos relacionados, etc.

4.6. Estrategias de comunicación, uso de la información adquirida y transferencia: que permiten utilizar eficazmente la información adquirida para tareas académicas y de la vida cotidiana, a través de técnicas como la elaboración de informes, la realización de síntesis de lo aprendido, la simulación de exámenes, las autopreguntas, los ejercicios de aplicación y transferencia, etc.

Desde nuestro punto de vista, nuestra clasificación abarca las tres dimensiones fundamentales de la mente humana: voluntad, capacidad y autonomía (querer, poder y decidir) (Beltrán, 2003; Beltrán, Pérez y Ortega, 2006; Weinstein, Husman y Dierking, 2002). Por un lado, se da el peso que merecen a las Estrategias Afectivas, Disposicionales y de Apoyo (Pintrich, Smith, García y Mckeachie, 1991; Roces, Tourón y González, 1995), fundamentales en el aprendizaje, con la valoración de la parte motivacional y afectiva ("querer-voluntad" es fundamental para "decidir-autonomía" y para "poder-capacidad") (Monereo, 1997; Pozo y Monereo, 1999). Por otro, se recogen suficientemente las Estrategias Metacognitivas (“decidir-autonomía”), que tienen que ver con la capacidad para tomar decisiones, planificar, autoevaluar el propio desempeño y autorregularse. Para terminar, se integran las Estrategias de Procesamiento de la información ("poder-capacidad") contempladas en las clasificaciones tradicionales (Adquisición, Elaboración, Organización y Almacenamiento), incluyendo las estrategias

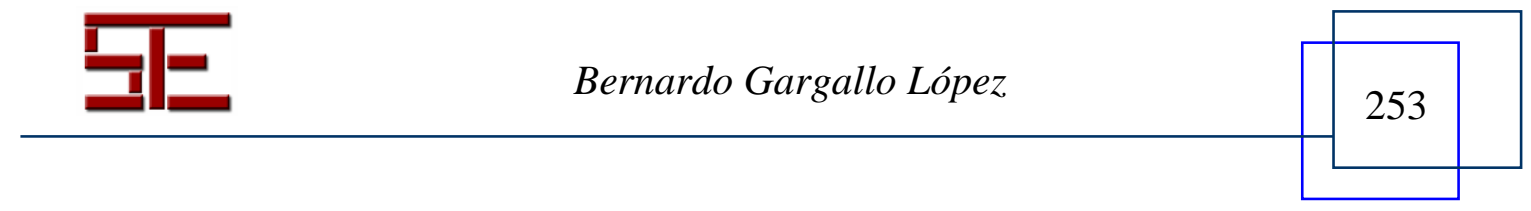




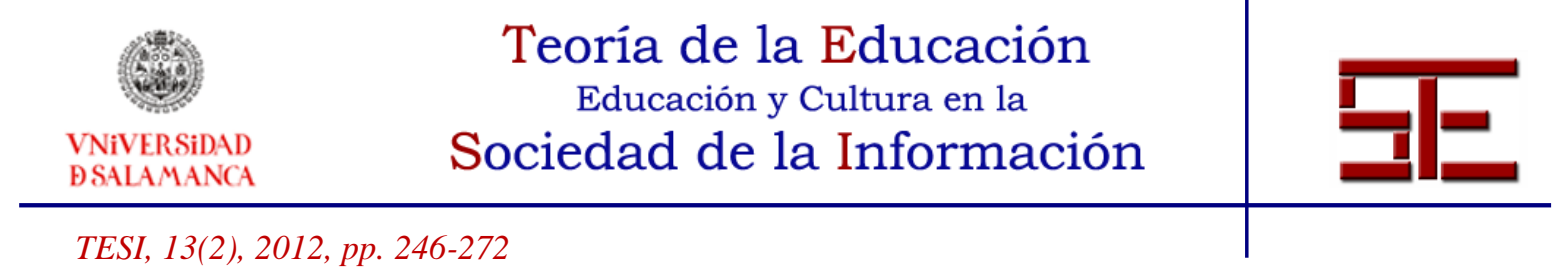

de Personalización, Creatividad y Pensamiento Crítico, así como las Estrategias de Recuperación y las de Transferencia y Uso, que suelen pasar desapercibidas en algunas de dichas clasificaciones. Así mismo, se incorporan las relacionadas con la Búsqueda y Selección de Información, típicamente olvidadas en las clasificaciones presentes en la literatura.

\section{3.- LA ENSEÑANZA DEL APRENDIZAJE AUTORREGULADO, DEL APRENDIZAJE ESTRATÉGICO}

La necesidad de abordar, de manera explícita, la enseñanza de las estrategias de aprendizaje en el ámbito escolar previo a la universidad es incuestionable. Es demasiado arriesgado pensar que los alumnos "aprenderán a aprender" por su propia cuenta. Ya hicimos referencia, antes, por otra parte, al aumento sustancial de la cantidad de conocimientos y de información disponibles y a la necesidad de desarrollar habilidades y estrategias para manejar la información y para continuar aprendiendo durante toda la vida. También lo es, incluso, en el universitario, dado que los alumnos no manejan adecuadamente las estrategias y habilidades necesarias.

\section{1.- La enseñanza antes de la universidad}

\subsection{1.- Alternativas disponibles}

Desde nuestro punto de vista, hay diversas alternativas disponibles en este empeño:

3.1.1.1.- Una es la aplicación de programas extracurriculares, entre los que se encuentran la mayoría de los programas de desarrollo cognitivo, algunos de ellos de cuidadoso diseño y gran complejidad, como es el caso del Proyecto Harvard de Desarrollo de la Inteligencia (Megía, 1992; Nickerson, Perkins y Smith, 1987), el F.I.E. (Feuerstein Instrumental Enrichment), en castellano P.E.I. (Programa de Enriquecimiento Instrumental) de Feuerstein (1988), o el Programa Aprender a Pensar, también denominado CORT (Cognitive Research Trust), de De Bono (1986) (Gráfico 1), por referirnos a tres programas de calidad en el ámbito de la enseñanza de las habilidades del pensamiento. Aparte de estos tres programas, hay otros de esta orientación (Alonso Tapia, 1990), como el Progresint, de Yuste (1991). Este tipo de programas, que tiene sus virtualidades, como es el proporcionar mucha práctica de habilidades básicas necesarias para enfrentarse a tipos más complejos de actuación cognitiva, presenta, también, algunas limitaciones.

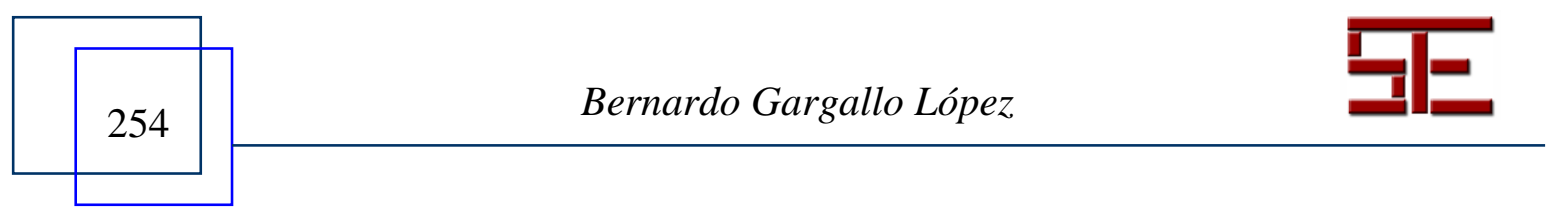




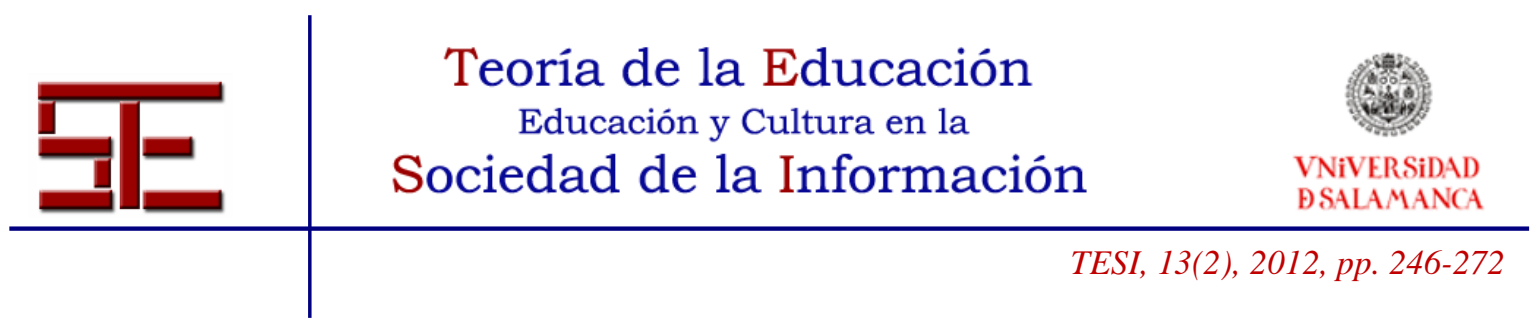

Una de ellas es el excesivo optimismo, al presuponer que el entrenamiento de unas cuantas habilidades básicas (que tampoco son coincidentes en todos ellos, lo que indica que la concepción de la inteligencia es diferente en unos y otros) basta para que el estudiante se enfrente a las diversas tareas escolares con armas y equipajes suficientes. Por otra parte, todos ellos están desprovistos de contenidos curriculares, vacíos de contenidos. Ello dificulta la transferencia de las habilidades a los ámbitos concretos de la actividad escolar, ya que ésta no se produce de manera automática.

También son, en muchas ocasiones, programas de tipo extracurricular muchos de los programas de enseñanza de técnicas de estudio, que se han venido aplicando en el sistema educativo. Vaya por delante que la sola enseñanza de técnicas de estudio no garantiza el aprendizaje estratégico, ya que ser aprendiz estratégico es mucho más que manejar una serie de técnicas. Las técnicas son herramientas que el aprendiz puede utilizar dentro de las estrategias junto con otros procedimientos para implementar los planes de acción articulados para afrontar con éxito el aprendizaje. Además, en muchas ocasiones, las técnicas de estudio se han enseñado fuera del currículo, alejadas de los materiales curriculares habituales y también en tiempos ajenos a los que los estudiantes pasan en la escuela y por profesionales que no son sus profesores. Un aprendizaje de esta índole no garantiza la generalización y transferencia de las habilidades adquiridas en estos programas al currículo ordinario.

3.1.1.2.- Otra alternativa es el diseño y aplicación de programas curriculares de enseñanza de estrategias de aprendizaje (Gráfico 1). Al hablar de programas curriculares estamos pensando en su aplicación dentro del aula, en horario escolar y sobre contenidos escolares habituales. Son los programas también denominados insertados, entroncados (Bernad, 1999), integrados o infusionados (Monereo, 1998). Nosotros nos decantamos por esta última opción, como ya hicimos en su momento (Gargallo, 2000), porque pensamos que es la más eficaz ya que favorece la transferencia de las habilidades aprendidas.

En esta opción también caben diversas posibilidades. Una es la enseñanza de estrategias específicas en contextos específicos, por tanto en las diferentes materias curriculares. Así, se entrenaría en estrategias específicas en Ciencias Sociales, en Lenguaje, en Matemáticas, etc.

Otra opción posible sería trabajar estrategias comunes a diversas áreas en esas mismas áreas. Esta opción tiene en común con el enfoque de programas generalistas que hemos visto antes la convicción de que hay determinadas habilidades, destrezas y estrategias que

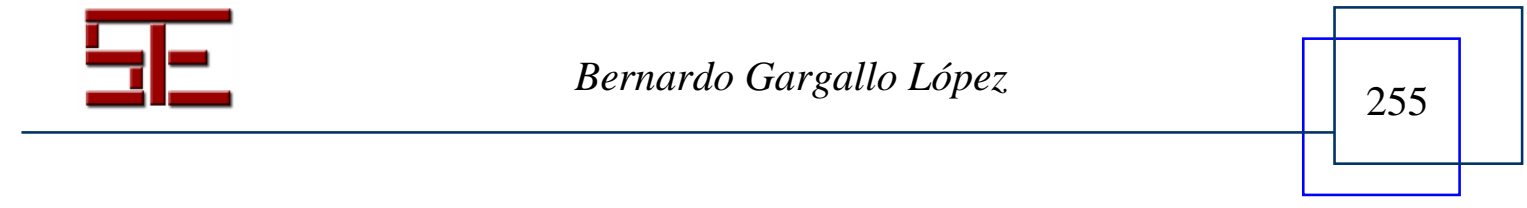




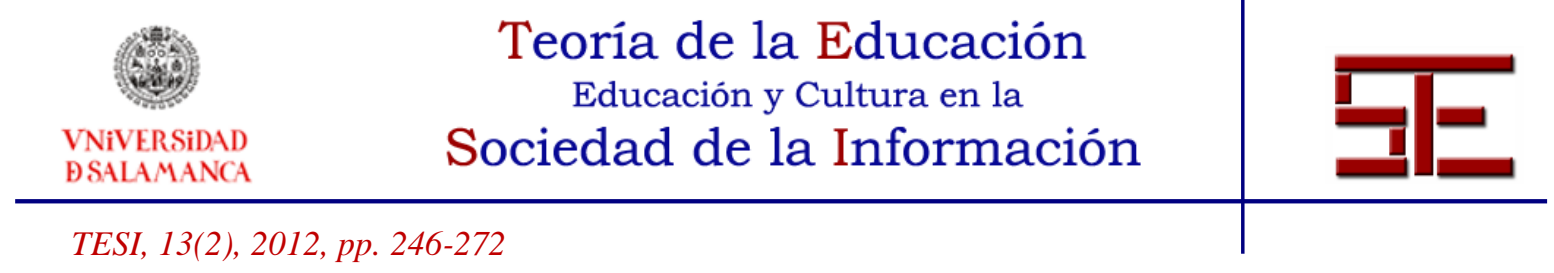

son comunes a diversas áreas y que se pueden utilizar en ellas (planificación, evaluación, elaboración y organización de la información, almacenamiento, etc...), pero se diferencia en que se trata de habilidades y estrategias contextualizadas, incardinadas en el currículum y aplicadas sobre contenidos curriculares, no vacías de contenido como se planteaban en el P.E.I. o en el Harvard.

Entendemos que ambos enfoques son complementarios, por otra parte, y no excluyentes. Se pueden enseñar y trabajar estrategias generales (en cuanto que sirven para aprender diversas materias) y también estrategias específicas propias de un área determinada (vgr. resolución de problemas matemáticos, lectoescritura, estrategias para Ciencias Naturales, etc.). Creemos que este enfoque "generalista contextualizado" es imprescindible para lograr que esas estrategias, las que no son específicas de ningún área, las que son "tierra de todos", sean trabajadas en el aula. Una excesiva disgregación y especialización en el tema podría resultar peligrosa en ese sentido, ya que estas estrategias quizá no fueran abordadas por ningún profesor, y acabarían convertidas en "tierra de nadie".

De hecho, nosotros hemos trabajado en esa doble dirección. Así, llevamos a cabo la aplicación de diversos programas: un programa educativo con alumnos de $8^{\circ}$ de Educación General Básica (13-14 años) en el ámbito de la enseñanza de estrategias de resolución de problemas matemáticos (Gargallo y Ruiz, 1994) y otro programa para enseñar estrategias cognitivas y metacognitivas de expresión escrita en $8^{\circ}$ de Educación General Básica (Gargallo, 1994). Estos dos programas se ubicarían en la que hemos denominado enseñanza de estrategias específicas en contextos específicos.

Posteriormente desarrollamos y aplicamos tres programas educativos en el ámbito de las estrategias orientadas a procesar y retener la información (entrenando a los sujetos en estrategias cognitivas, metacognitivas y afectivo-motivacionales y de apoyo). El primero de ellos se aplicó sobre sujetos de $6^{\circ}$ de Primaria (Gargallo, 1997) con veintitrés sesiones a lo largo de tres meses. El segundo sobre estudiantes de un centro de Educación Permanente de Adultos. (Gargallo y Puig, 1997) con cuarenta sesiones aplicadas a lo largo de seis meses. Y el tercero sobre estudiantes de $1^{\circ}$ y $2^{\circ}$ de Educación Secundaria Obligatoria y sobre estudiantes de Educación Permanente de Adultos (Gargallo y Ferreras, 2000). En este caso se trata de programas que trabajan estrategias comunes a diversas áreas en esas mismas áreas.

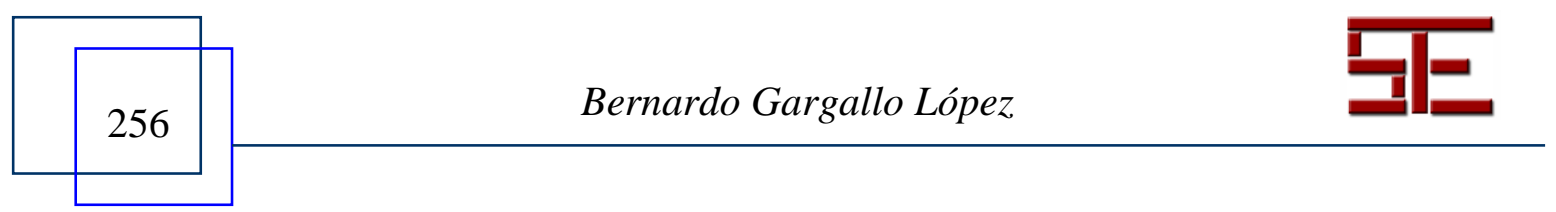




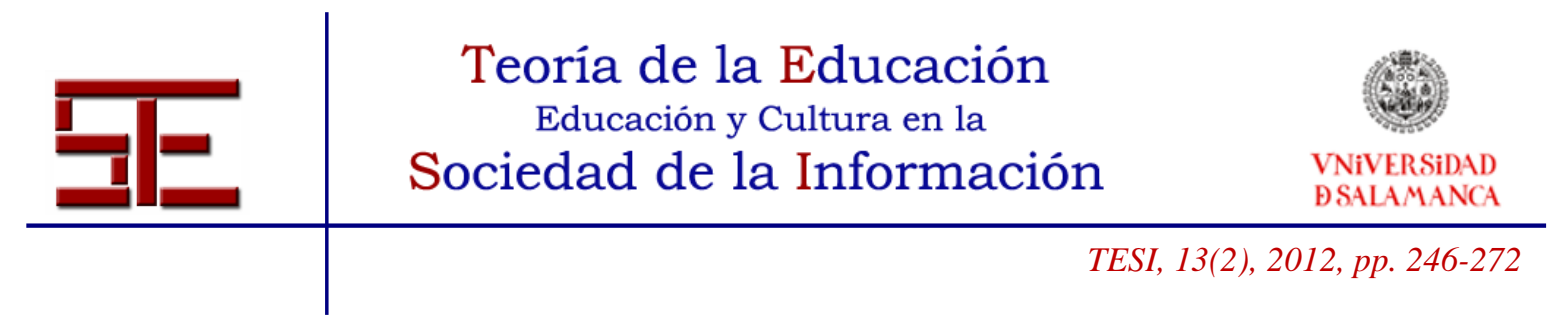

Gráfico 1. Alternativas disponibles para la enseñanza de las estrategias de aprendizaje

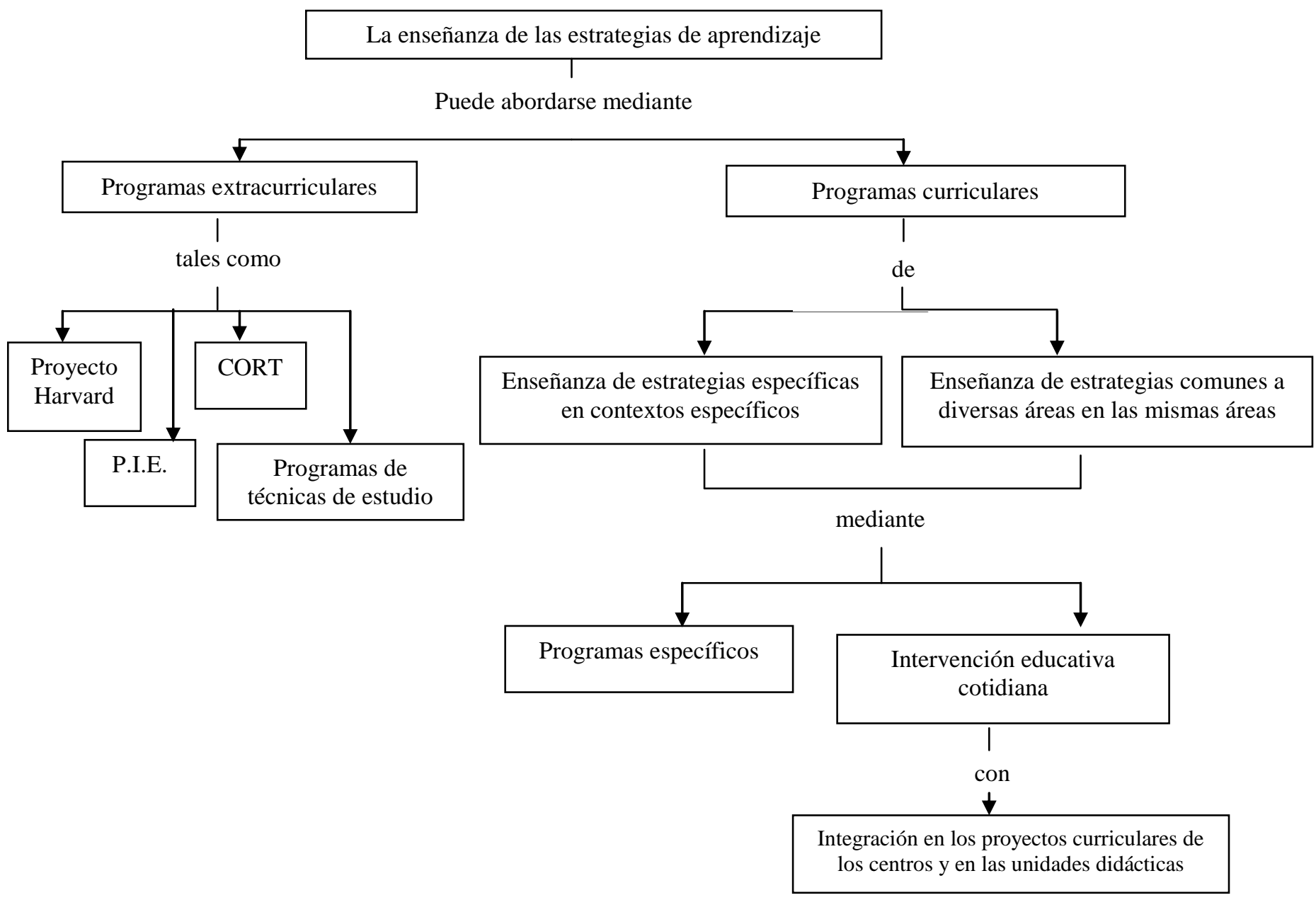

Otros investigadores han desarrollado también trabajos exitosos insertos en el currículum (Ortiz, Salmerón y Rodríguez, 2007).

En esta segunda opción que se decanta por los programas curriculares, existen también dos alternativas: aplicar programas específicos de enseñanza de estrategias cognitivas y

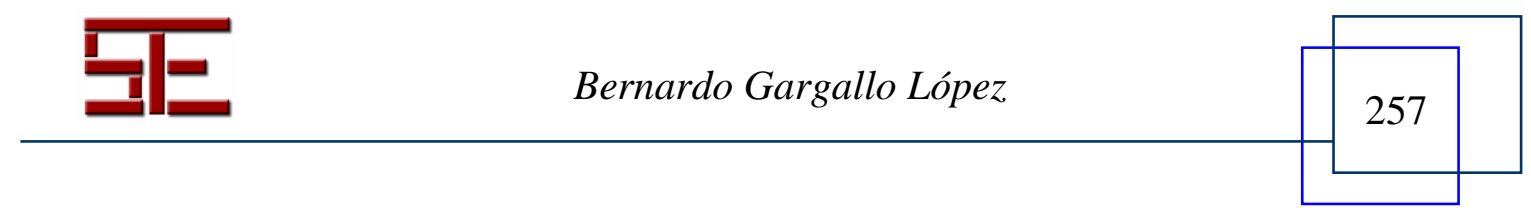




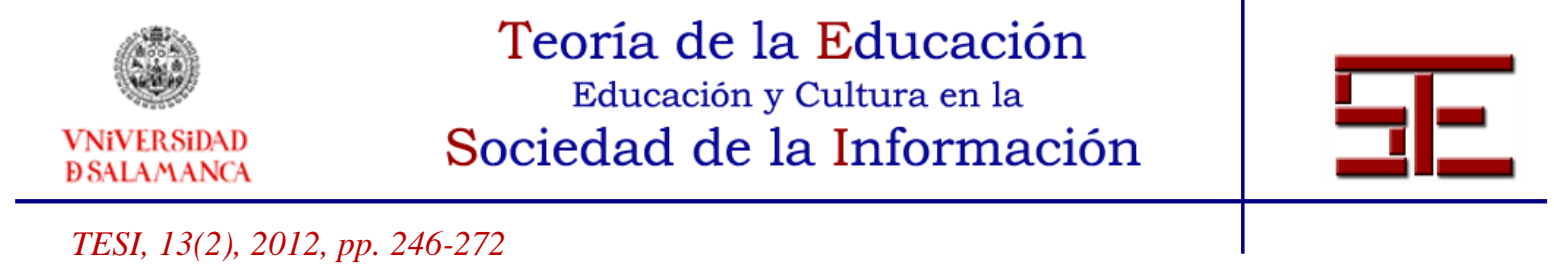

metacognitivas concretas mediante las técnicas pertinentes y durante un tiempo determinado del curso (dos o tres meses, generalmente) o abordar su enseñanza en el día a día de la intervención educativa de los profesores y en todas y cada una de las unidades didácticas de las diversas disciplinas.

En la primera línea hemos venido trabajando nosotros. En ella se incardinan los trabajos a los que antes hemos hecho mención. Este tipo de trabajos es positivo ya que implica a los profesores, que elaboran y aplican los programas con los investigadores, toman conciencia del problema y aprenden métodos y técnicas de intervención que, en su momento, les permitirán abordar la enseñanza del pensar de modo sistemático e integrador, en su intervención diaria. Éste es el objetivo al que hay que tender, desde nuestro punto de vista, ya que la alternativa más adecuada es la integración de la enseñanza de las estrategias de aprendizaje en el día a día de la acción educativa y en todas las asignaturas.

\subsection{2.- Elementos fundamentales para la integración}

Elementos críticos para la integración son la política del centro y su proyecto curricular, que puede hacer suyo el proyecto de inserción de las estrategias como eje relevante, la disponibilidad de asesores/orientadores competentes en los centros, que constituyen una ayuda inestimable para la integración en el currículum por parte de los profesores del aprender a aprender. Y, por supuesto, el compromiso de los profesores: enseñantes estratégicos-aprendices estratégicos.

Los profesores son, en último término, los agentes clave para la inclusión de las estrategias en el currículum. Sin su compromiso e implicación todo lo demás puede quedarse en papel mojado o en declaraciones de buenas intenciones. Para una actuación eficaz deben tener formación sobre el tema, ya sea previa al ejercicio profesional, ya durante el mismo. Los profesores con formación en este territorio son más sensibles a las demandas y necesidades de los estudiantes y están más dispuestos a enseñarles a "aprender a aprender".

Hay que ser conscientes de que en ocasiones se encuentra una cierta reticencia por parte de los profesores cuando se les plantea la pertinencia de abordar en el currículum la enseñanza de las estrategias de aprendizaje. Existe la sospecha de que esta tarea comportará mucho más trabajo y un esfuerzo añadido al que ya los compromete la enseñanza cotidiana a que están acostumbrados. Sin embargo, no dejan de ser reticencias infundadas. La reflexión pertinente es que la clave está en enseñar los contenidos de otra manera, en abordar la enseñanza de manera estratégica: no es posible lograr que los

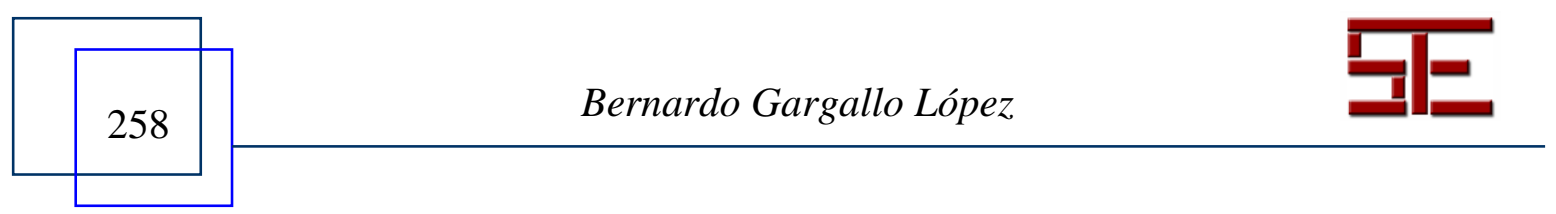




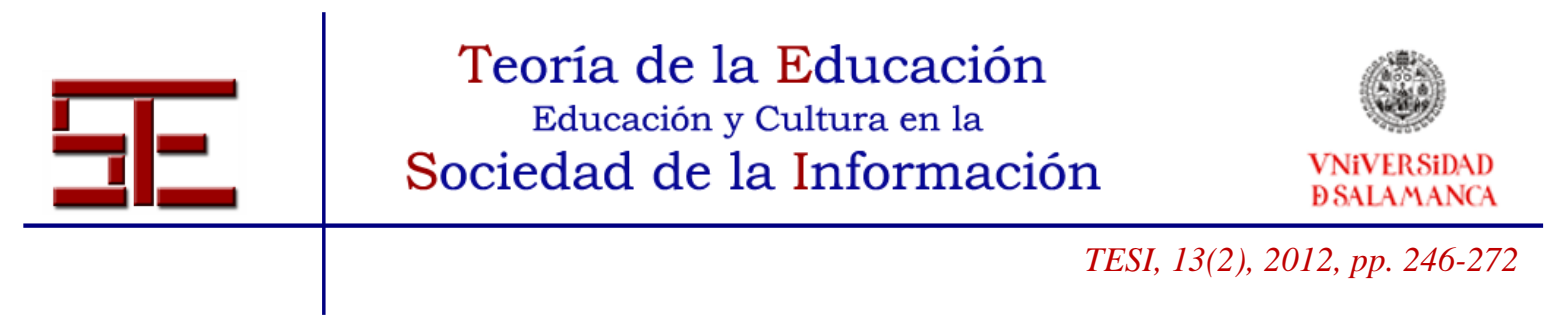

estudiantes sean aprendices estratégicos sin profesores que, a su vez, sean también estratégicos: en educación el medio es el mensaje, ya que los modos de enseñar también se aprenden. Se trata de instaurar una nueva cultura docente en que se enfaticen no sólo los resultados, sino también los procesos, potenciando la reflexión en torno a los mismos y la optimización de los modos de aprender.

Cualquier tarea de aprendizaje puede ser enseñada estratégicamente; para ello es muy recomendable que el profesor enseñe y modele previamente, ayudado por los alumnos especialmente por los más competentes- cuando ello sea posible, la resolución de la tarea explicitando y verbalizando los objetivos de la misma, los procedimientos de solución disponibles, la elección consciente de alternativas, la justificación del proceso seguido, la revisión y evaluación del propio trabajo, etc.

Se trata, pues, de enfatizar y enseñar el proceso de solución de la tarea para ayudar a construir una guía de trabajo, que debe ser clarificada, negociada y reelaborada por el grupo y por cada sujeto -no se trata de aprender de manera inflexible y mecánica un procedimiento de solución, sino de ajustarlo a los requerimientos de la tarea y a la idiosincrasia personal-. A partir de ahí se trata de practicar la estrategia en cuestión, dirigidos por el profesor, por un compañero experto o por algún instrumento consensuado vgr. una hoja guía de solución de problemas, una hoja guía de elaboración de mapas conceptuales, una hoja guía de redacción de composiciones escritas, etc.-, asesorados por el docente, para llegar progresivamente a la interiorización del procedimiento. Posteriormente, mediante la práctica independiente del procedimiento el alumno irá consiguiendo su automatización, que le permitirá llegar a ser experto en su uso. Cuando los alumnos dispongan ya de una cierta competencia en torno a la estrategia en cuestión, es muy pertinente, para ayudar a que ésta se afiance significativamente, la utilización, por parte del profesor, del cuestionamiento, del planteamiento de preguntas en torno al proceso, para aclarar dudas, reforzar elementos todavía no automatizados, etc.

Es necesario, también, abordar la evaluación en esta perspectiva, para fomentar el aprendizaje estratégico, elaborando sistemas de evaluación que exijan la reelaboración de lo enseñado y no sólo su reiteración, planteando la situación de evaluación y examen como una oportunidad especial para aprender sobre la materia, a partir de la aplicación autónoma de las estrategias aprendidas, no como un punto y final de una serie de temas que se olvidarán después. La evaluación, en esta perspectiva, cobra, si cabe, un carácter todavía más procesual y formativo que aplicada a otros contenidos. El aprendizaje de habilidades nunca es cuestión de todo o nada, sino un proceso gradual en que se van desarrollando

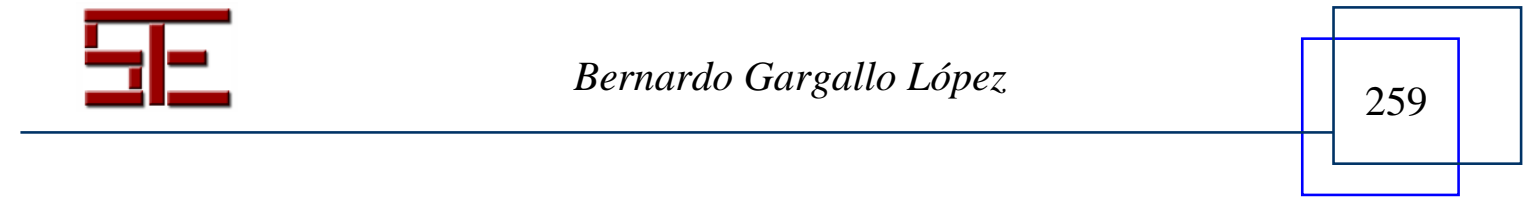




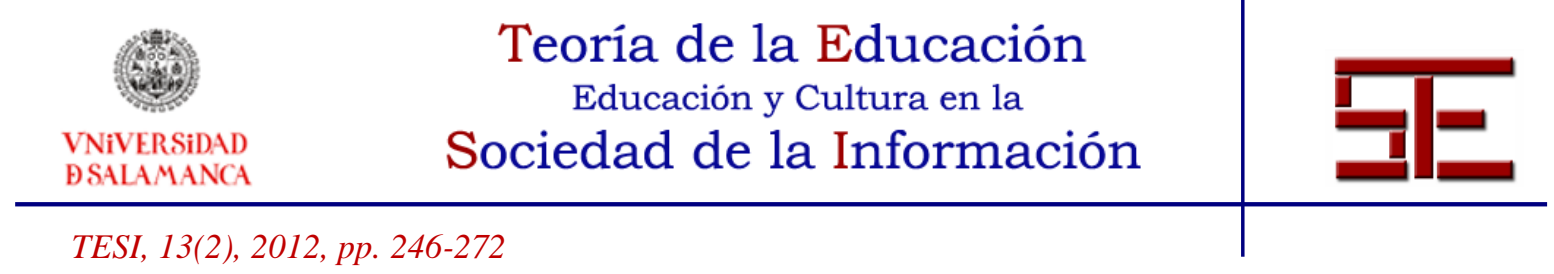

niveles progresivos de competencia que van desde el tanteo primerizo hasta llegar a la conciencia y control del uso de la estrategia -interiorización- y al dominio del experto (ley de doble formación vygotskyana). Reclama, pues, seguimiento continuo, para detectar y diagnosticar las dificultades, interacción constante profesor-alumno y asesorar y prestar ayudas que se van retirando conforme el alumno progresa (andamiaje en término de Bruner).

\subsection{3) Una secuencia para la enseñanza y técnicas para trabajarla}

Partiendo de las aportaciones de diversos investigadores expertos en el tema (Beltrán, 1993; Monereo, 1994 y 1998; Nisbet y Shucksmith, 1987) y de nuestros propios trabajos, proponemos, como deseable, el siguiente formato, para la enseñanza de estrategias de aprendizaje:

1) Análisis de la realidad. Detección de los conocimientos previos y contextualización de la intervención, que requiere análisis de las demandas del escenario escolar, de los medios y recursos disponibles, exploración de lo que los alumnos ya saben en manejo de estrategias, etc.

2) Planificación, que supone formular objetivos, concretar qué estrategia o estrategias se van a trabajar, precisar claramente la secuencia de cada una de ellas, dividiéndola en habilidades, establecer criterios e instrumentos de evaluación, elegir la metodología de enseñanza, precisar los tiempos, etc.

3) Presentación didáctica de la estrategia. Es conveniente la guía directa del profesor, que puede realizarse a través de dos métodos/técnicas adecuados para ello: la instrucción directa y el modelado.

- La enseñanza-instrucción directa e interactiva: se trata de explicitar lo que se va a aprender, las razones para el aprendizaje, y de proporcionar a los alumnos indicaciones detalladas del uso correcto de la estrategia (Pérez Cabaní, 1998).

Pasos:

-Motivar a los estudiantes, "vender el producto".

-Descripción de la estrategia.

-Exposición de los pasos que se deben seguir.

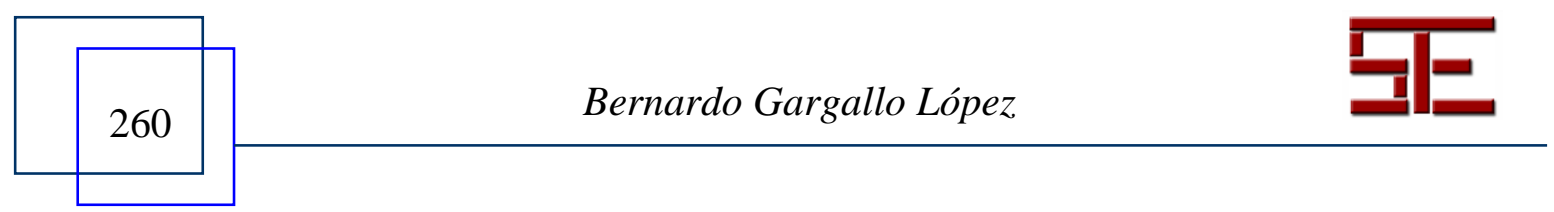




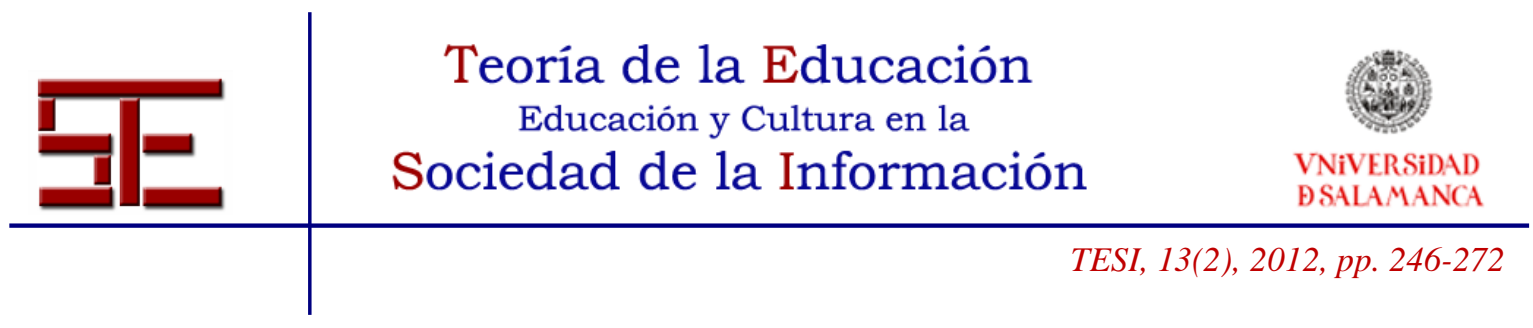

-Análisis de las situaciones en que será útil

-Concreción de los criterios que permitirán decidir su utilidad y adecuación en una situación concreta.

- El modelado de la estrategia en cuestión: es una técnica privilegiada para la enseñanza de las estrategias de aprendizaje (Beltrán, 2003; Monereo, 1994, 1997; Nisbet, 1991). Implica la realización de la tarea por un experto, profesor, padre, adulto o igual, de forma que los estudiantes puedan observar y construir un modelo conceptual de los procesos que se requieren para realizar la tarea. En dominios cognitivos, y el ámbito de las estrategias lo es, el modelado exige la externalización de los procesos cognitivos y metacognitivos (planificación, control y revisión/evaluación) que el experto moviliza.

4) Práctica guiada de la estrategia en diferentes contextos: de modo que los alumnos utilicen la estrategia en alguna actividad, guiados por el profesor y/o por la guía de uso elaborada. En esta fase es muy pertinente, a partir del uso de la estrategia por parte de los alumnos, la detección de errores o elementos poco claros o innecesarios, la modificación y adaptación de la guía de uso de la estrategia.

Excelentes técnicas para la práctica guiada son el cuestionamiento, la autointerrogación metacognitiva, el trabajo en grupos cooperativos y la enseñanza recíproca (Pérez Cabaní, 1998):

- El cuestionamiento, planteamiento de preguntas o interrogación, también conocido como mayéutica o método socrático de enseñanza: Brown y Campione (1979) adjudican al profesor el papel de "abogado del diablo", que cuestiona constantemente las suposiciones y premisas básicas del estudiante. El objetivo de la técnica es lograr que los alumnos se hagan conscientes de sus propios procesos de pensamiento (Nisbet, 1991; Nisbet y Shucksmith, 1987; Monereo, 1994, 1997). La clave está en la utilización de buenas preguntas: "¿Cómo lo has hecho?", "¿Por qué lo haces así?", "¿Por qué has dicho esto?", "¿Puedes justificarlo?", "¿Existen otras alternativas?", etc.

- La autointerrogación metacognitiva: su aplicación (Tei y Stewart, 1985; Tomlinson, 1987) precisa de la elaboración previa de un modelo de interrogación que ha de contener una serie de cuestiones a las que el alumno tiene que responderse en tres momentos o fases, antes de comenzar la tarea,

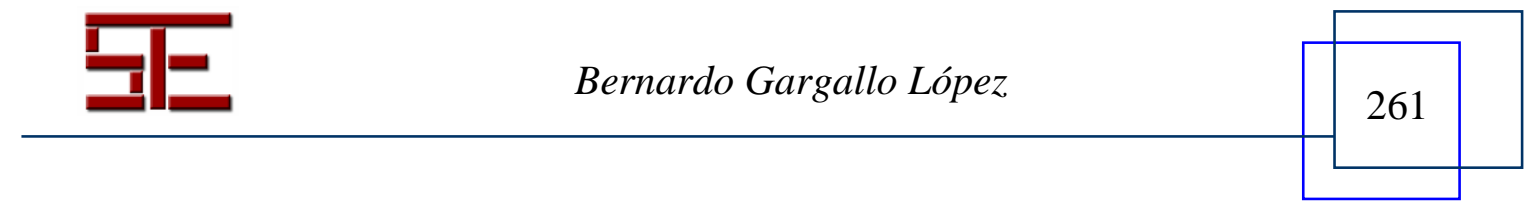




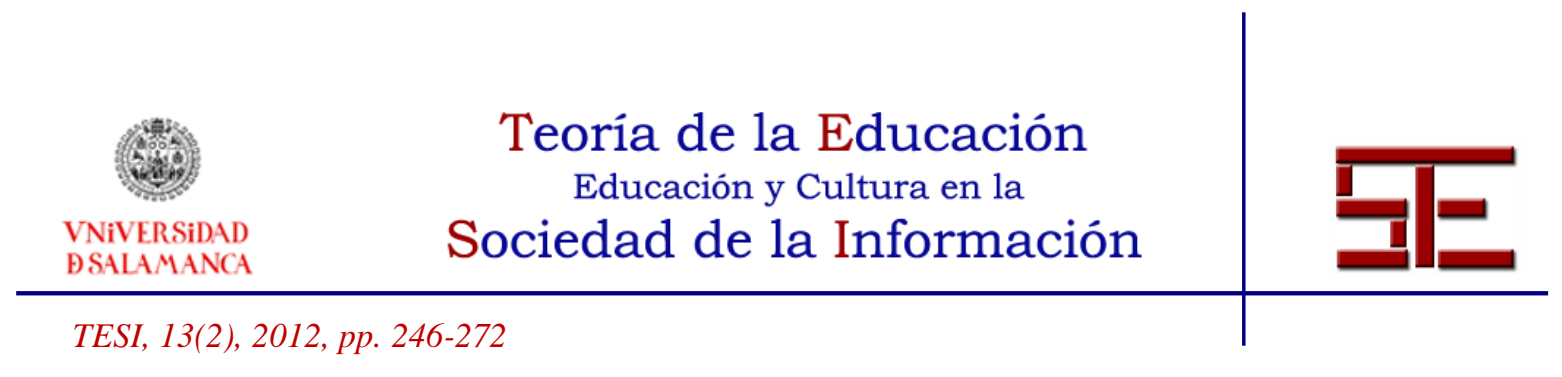

durante la ejecución de la misma y al concluirla. El procedimiento prevé una ayuda del profesor desde el inicio, que va disminuyendo hasta conseguir que el alumno interiorice el procedimiento y pueda utilizarlo de forma independiente en diversas situaciones de aprendizaje. Cada profesor puede elaborar su propio modelo de interrogación y experimentar sobre la práctica su aplicación.

- El trabajo en grupos cooperativos: el objetivo de la técnica es promover la realización conjunta de tareas enriqueciendo la perspectiva propia con la de los otros y aprender todos de todos. El aprendizaje cooperativo propicia el diálogo y la discusión en torno a la naturaleza del aprendizaje y las tareas académicas, permite negociar significados y potencia el desarrollo de la metacognición al favorecer la reflexión y autoevaluación (Pérez Cabaní, 1998).

Algunos principios de uso:

- Favorecer la interdependencia entre los miembros del grupo constituyendo grupos heterogéneos con diferentes funciones y responsabilidades.

- Presencia activa del profesor que proporciona retroalimentación al grupo y a sus miembros.

- Cada miembro del grupo debe colaborar activamente asumiendo su responsabilidad.

- El grupo debe tener tiempo suficiente para discutir sobre la tarea.

Antes de iniciar el proceso hay que planificar y situar la actividad (explicar la tarea y dejar clara la función de cada miembro, fomentar la cooperación, especificar los criterios de evaluación, etc.). Durante el proceso hay que guiar e intervenir (organizando la interacción, favoreciendo la interacción y el intercambio verbal, controlando la comprensión, ofreciendo feed-back, sugiriendo, etc.). Al finalizar hay que evaluar el proceso (analizando el funcionamiento del grupo y viendo cómo se han utilizado las habilidades, evaluando el proceso conjuntamente, valorando la adecuación de los procedimientos que se han utilizado, formulando conclusiones que resuman los aspectos principales del tema tratado).

- La enseñanza recíproca: se trata de que también los alumnos puedan ejercer de profesores, de modo que se expliquen unos a otros cómo desarrollar la estrategia de que se trate, la ejecuten delante de sus compañeros y dirijan su puesta en acción. Es una técnica también muy adecuada ya que, cuando se

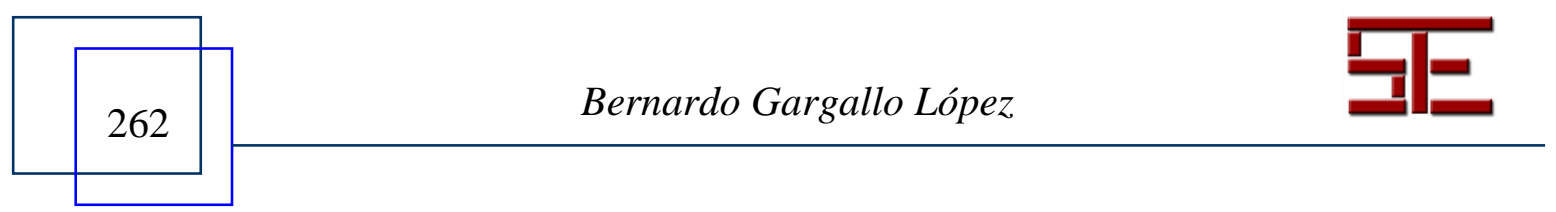




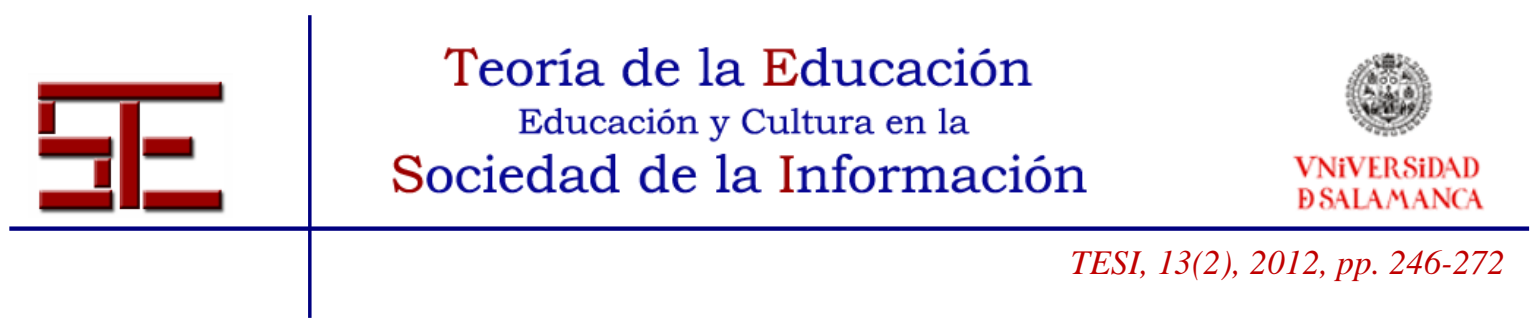

explica algo a otros, el "profesor" lo aprende mucho mejor. Los alumnos van intercambiando sus papeles, de modo que unos hacen unas veces de profesores y otras veces lo hacen otros. El profesor ha de mantener una presencia activa ejerciendo de mediador y facilitando la retroalimentación necesaria.

5) Interiorización de la estrategia: el profesor retira la guía y pide a los alumnos que la interioricen.

6) Práctica independiente: los estudiantes utilizan la estrategia con autonomía en actividades similares a las de práctica guiada. Para favorecer la práctica independiente disponemos de la técnica de cuestionamiento, de la autointerrogación metacognitiva, el trabajo en grupos cooperativos y de la técnica de instrospección:

- La introspección, también denominada análisis y discusión metacognitivos. Esta técnica (Nisbet, 1991; Nisbet y Shucksmith, 1987) tiene como objetivo identificar y valorar los procesos de pensamiento subyacentes a una tarea de aprendizaje con el fin de que los alumnos sean conscientes de la eficacia de los procedimientos que utilizan y de la de los que utilizan sus compañeros, de modo que los puedan modificar (Pérez Cabaní, 1998). Consiste en verbalizar los procesos cognitivos que se ponen en marcha para llevar a cabo tareas escolares. Para ello se enfrenta a los estudiantes a tareas escolares (estudio, resolución de problemas, escritura, realización de trabajos, deberes, etc.) y, al mismo tiempo, se les pide que describan su método de trabajo, oralmente o por escrito. Posteriormente se analizan, se dan a conocer y se someten a crítica ante el grupo de clase las diferentes estrategias explicitadas, aprendiendo unos alumnos de otros.

7) Entrenamiento en prácticas de generalización, transfer y fomento del mantenimiento a largo plazo: como en el caso anterior, se trata de una condición necesaria que debe acompañar el proceso de enseñanza aprendizaje. Para lograrlos, hay que enseñar el "cómo", "cuándo" y "por qué" del uso de la estrategia. También se deben ofrecer a los alumnos oportunidades para aplicarla y transferirla...

8) Evaluación: debe ser predominantemente procesual y formativa para mejorar continuamente el proceso, utilizando, en todo caso, pruebas relacionadas con los objetivos del programa, pruebas similares a las empleadas en la instrucción, para valorar la destreza y dominio en el uso de la estrategia.

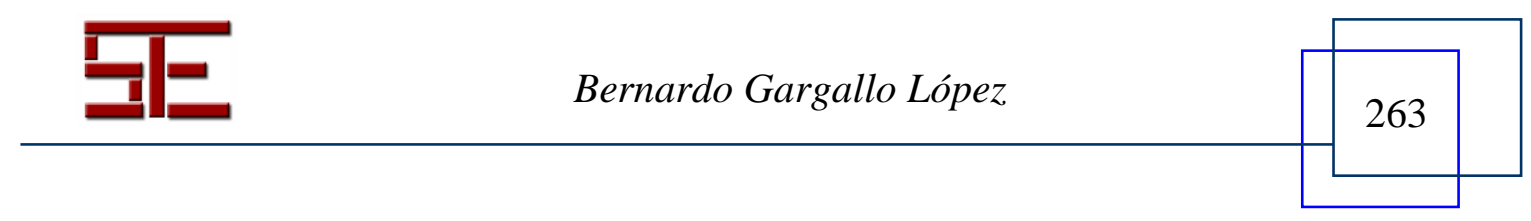




\begin{tabular}{c} 
Teoría de la Educación \\
Educación y Cultura en la \\
$\begin{array}{c}\text { VNiVERSIDAD } \\
\text { BSALAMANCA }\end{array}$ \\
\hline TESI, 13(2), 2012, pp. 246-272
\end{tabular}

9) Instrucción explícita en procesos de regulación y autocomprobación del aprendizaje (metacognición): No es tanto una fase como una condición de calidad de todo el proceso de enseñanza-aprendizaje, al que debe acompañar. Se debe ofrecer feed-back correctivo individual que permita contrastar la ejecución del estudiante con un modelo de uso eficaz de la estrategia, utilizar el diálogo para pedir a los alumnos que expliciten los pasos que dan, etc.

Gráfico 2. Secuencia para la enseñanza y técnicas

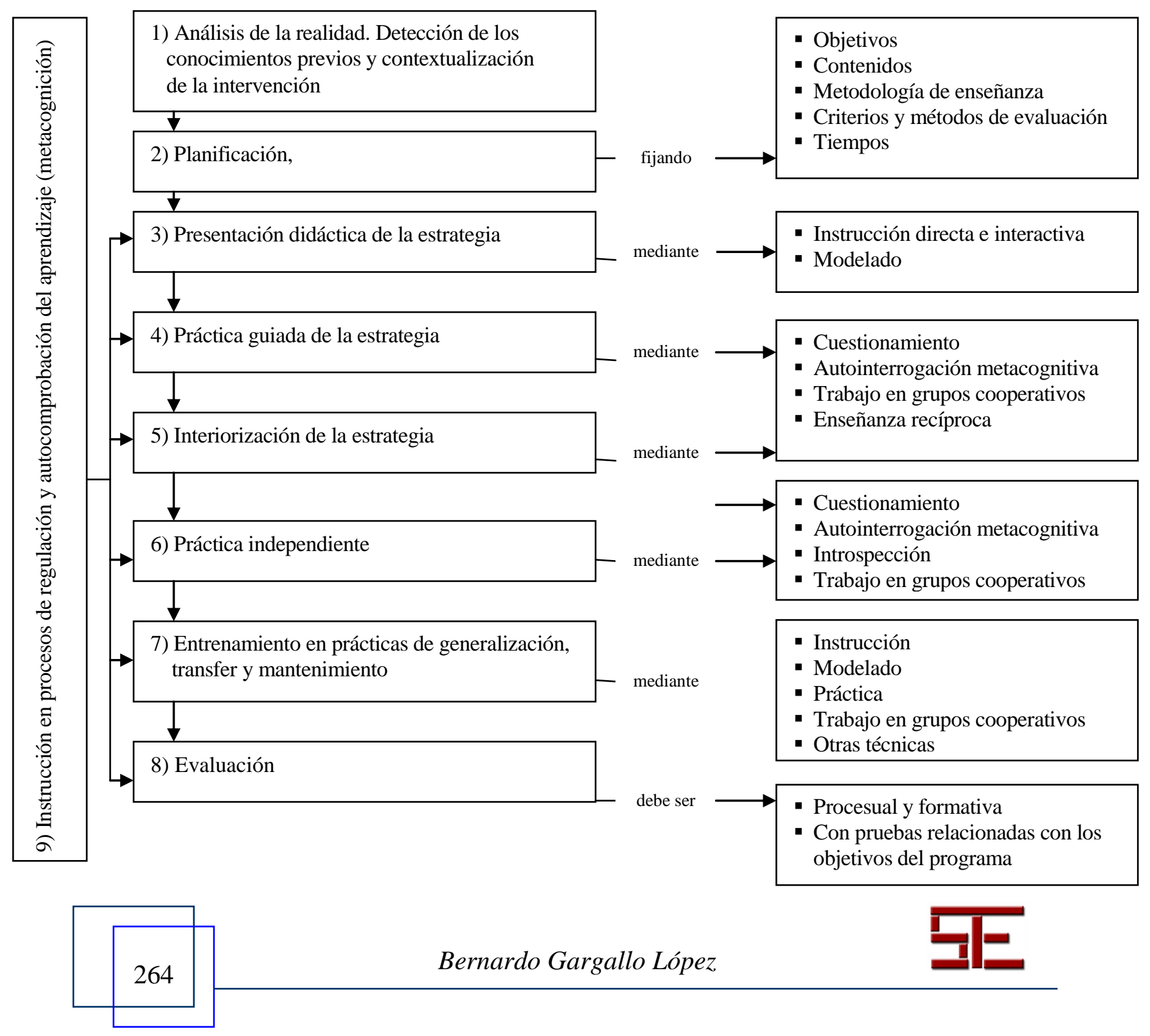




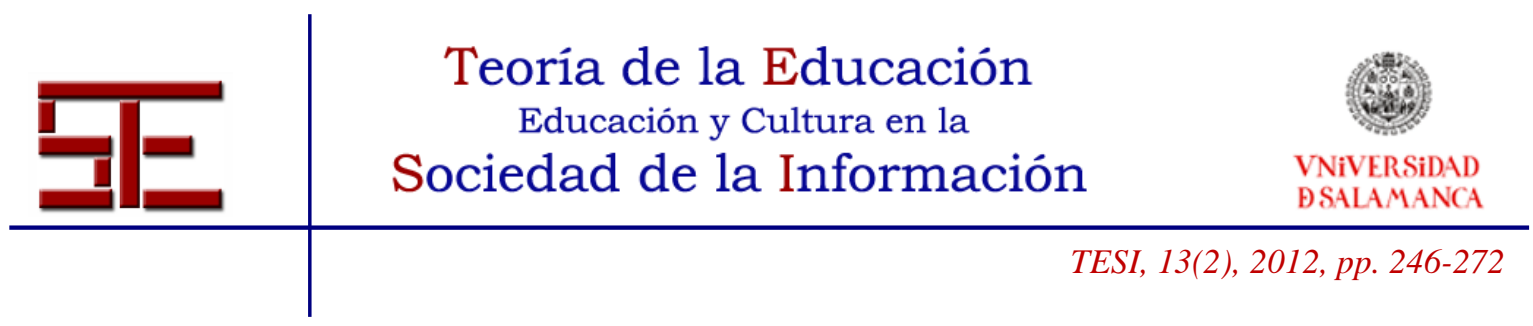

\section{2.- La enseñanza del aprendizaje estratégico en la universidad}

La experiencia contradice el deseo de los profesores universitarios de que los estudiantes sean lo suficientemente competentes en aprendizaje autorregulado, en manejo de estrategias de aprendizaje. A partir de la constatación de las deficiencias, cabe la inhibición ("no es responsabilidad nuestra, debieran manejarse bien ya que son adultos... y han llegado a la universidad") o el compromiso docente y la acción para ayudarlos, lo que nosotros defendemos. Un argumento más son los datos de las investigaciones que prueban que los estudiantes con buenas estrategias de aprendizaje obtienen mejores rendimientos académicos: Cano y Justicia (1993), Pintrich (1995), Valle y Rodríguez (1998), Camarero, Martín y Herrero (2000), Gargallo (2006), Gargallo, Suárez y Ferreras (2007), Gargallo, Suárez-Rodríguez y Pérez-Pérez (2007). Por fin, hay demasiado fracaso y abandonos en los primeros cursos.

El trabajo en este entorno en la universidad presenta diversas alternativas, que describimos sucintamente:

\subsection{1.- La aplicación de programas específicos}

Durante un periodo determinado de tiempo, con un número de sesiones delimitadas y con una secuencia bien articulada, unas veces dentro del periodo lectivo de clase y otras fuera del mismo, se enseñan ciertas estrategias y habilidades. Normalmente sirven para desarrollar investigaciones y probar herramientas que puedan generalizarse a partir de la validación de las hipótesis.

Algunos trabajos publicados en esta dirección son el de Norton y Crowley (1995), en que se entrenó a alumnos en primer curso de carrera en habilidades de estudio, estrategias y enfoques de aprendizaje, como parte del currículum de psicología (Liverpool Institute of Higher Education). Los alumnos entrenados elaboraron una concepción de aprendizaje más sofisticada, mejoraron sus habilidades y estrategias, y desarrollaron enfoques más profundos. También obtuvieron mejor rendimiento académico que los no entrenados.

Y el de de Rosàrio y otros (2007), en que los alumnos fueron entrenados en estrategias cognitivas, metacognitivas y de apoyo. Se logró mejora en su conocimiento de estrategias y en el manejo de las mismas, al tiempo que también se desarrolló enfoque profundo de aprendizaje. También obtuvieron mejor rendimiento académico que los no

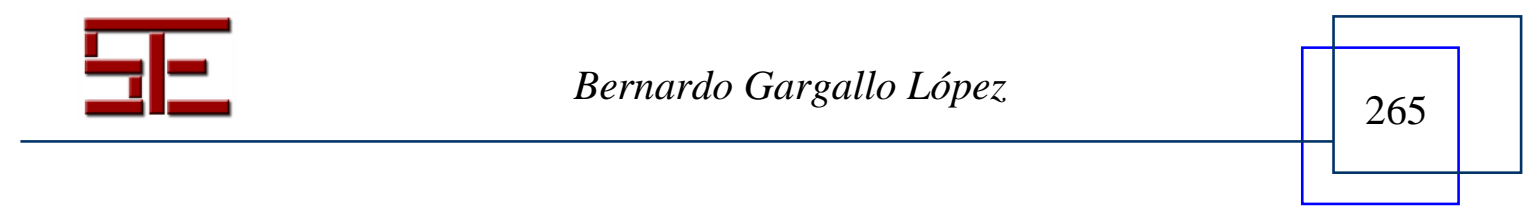




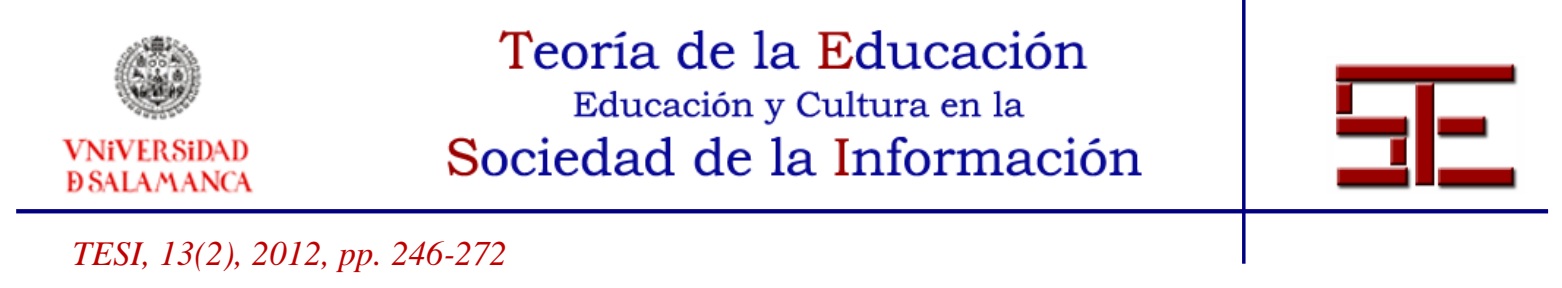

entrenados. El programa se aplicó sobre estudiantes de 1er curso de dos titulaciones de la Universidad de Oviedo (España) (6 sesiones, una por semana, de 1 hora de duración, aplicadas entre octubre-diciembre de 2005).

\subsection{2.- El diseño de asignaturas o talleres de libre asistencia de los alumnos}

En el caso de los talleres, durante un periodo de tiempo breve y con un número de sesiones delimitadas (en torno a 10 horas, más o menos), se enseñan ciertas estrategias y habilidades a los estudiantes que lo desean (así procede, por ejemplo, el ICE de la Universidad Politécnica de Valencia).

En el caso de asignaturas el tiempo es mayor, y también se entrena en estrategias y habilidades. Un ejemplo de este planteamiento sería la asignatura de libre elección, diseñada por el autor de este trabajo, denominada "Estrategias de aprendizaje y técnicas de estudio para estudiantes universitarios", de 4 créditos, ofertada en uno de los campus de la Universidad de Valencia para estudiantes de primeros cursos, que se ha venido impartiendo desde 2003-2004 hasta su desaparición en el curso actual, por la lógica de la denominada optimización de recursos.

\subsection{3.- La inserción en las titulaciones de materias obligatorias de tipo instrumental}

En esta opción, generalmente en el primer curso, se enseñan estrategias y habilidades que se consideran necesarias para el buen manejo en la universidad. Se trata de asignaturas obligatorias, que son parte del currículum del estudiante, de los grados. Un ejemplo de este planteamiento es la asignatura de $1 \mathrm{er}$ de los títulos de grado de Pedagogía y Educación Social de la Universidad de Valencia, denominada "Estrategias para el aprendizaje y la participación en la universidad". Se trata de una asignatura de 6 créditos organizada en cuatro talleres:
1. Dinámica de grupos (15 horas)
2. TIC y Documentación (15 horas)
3. Estrategias de aprendizaje (15 horas)
4. Conocimiento y participación en la vida universitaria (15 horas)

Hemos recogido datos del curso actual en las dos titulaciones a través de varios instrumentos (de evaluación de estrategias, enfoques, actitudes y autoconcepto), que nos

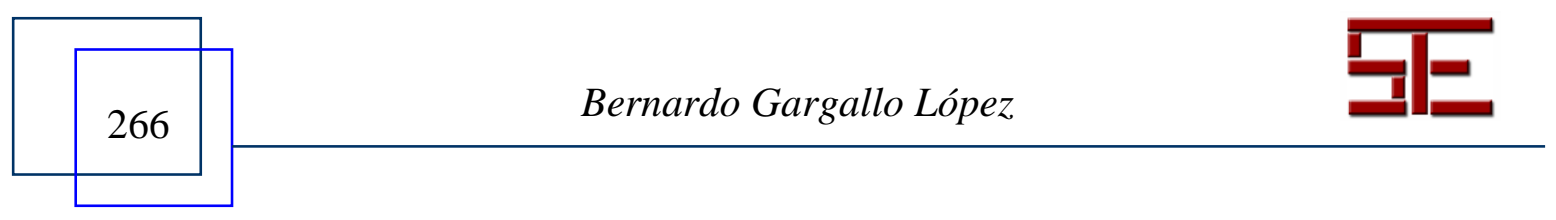




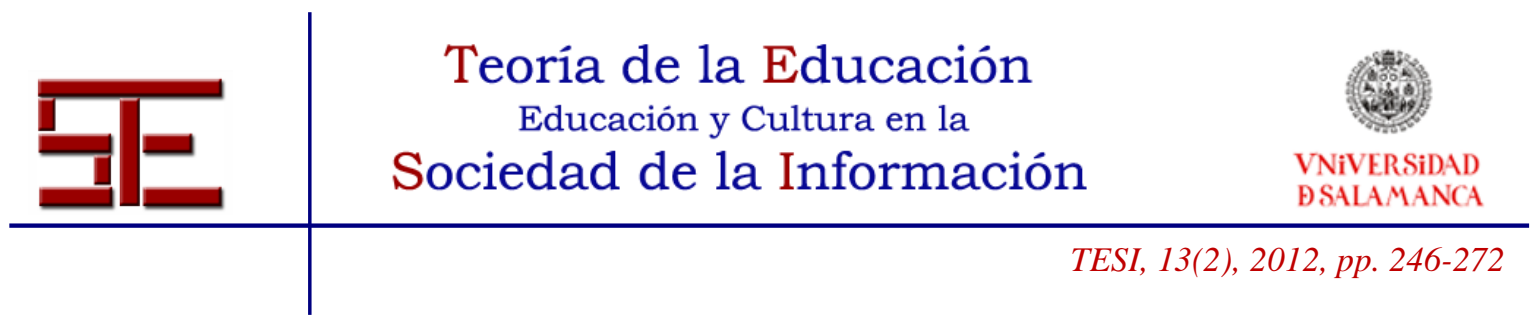

permitirán valorar su impacto, considerando también el rendimiento y la valoración de los estudiantes de la materia, de los que tenemos datos todavía pendientes de analizar.

3.2.4.- La inserción en el currículum de las materias del aprendizaje estratégico, por medio de la acción de los profesores

Los profesores, en sus asignaturas, enseñan a los alumnos a aprender a aprender la materia, trabajando en ellas las estrategias y habilidades necesarias: manejo de fuentes documentales y estrategias para seleccionar la información, elaboración y organización de la información, planificación, evaluación y autorregulación, realización de trabajos e informes, etc.

No disponemos de datos científicos directos de la evaluación de esta aproximación al tema, pero sí indirectos: sabemos que los métodos de enseñanza y evaluación de los profesores influyen en los modos de aprender de los estudiantes y en su rendimiento académico (Gargallo, Garfella, Pérez y Fernández, 2010). Son datos provenientes del proyecto de $\mathrm{I}+\mathrm{D}+\mathrm{I}$ "Estrategias de enseñanza y estrategias de aprendizaje en la universidad. Análisis de la incidencia de variables fundamentales en los modos en que los alumnos afrontan el aprendizaje" (código SEC2003-06787/PSCE). Estos datos muestran que los profesores centrados en el aprendizaje y con habilidades docentes logran que sus estudiantes mejoren en estrategias de aprendizaje, en actitudes ante el aprendizaje, en enfoques de aprendizaje y también en rendimiento académico.

En definitiva, caben y son necesarios diversos modos de acción de los docentes universitarios, no alternativos sino complementarios en la mayoría de los casos, para mejorar las estrategias de aprendizaje de sus alumnos. La implementación de asignaturas de tipo transversal es compatible con la actuación orientada al aprendizaje del profesor en el aula.

\section{4.- LA ORIENTACIÓN, LOS VALORES Y LAS ACTITUDES}

Estamos convencidos de que el aprendizaje autorregulado, el aprendizaje estratégico, son excelentes herramientas para aprender. De hecho, los estudiantes que manejan bien las estrategias de aprendizaje aprenden más y mejor y obtienen mejor rendimiento académico que los que no lo hacen (valorando el rendimiento académico por medio de las calificaciones). Pero ha de ser un aprendizaje "orientado", diríamos que para aprender más y mejor, pero con horizonte, con finalidades, con valores. Aprender más

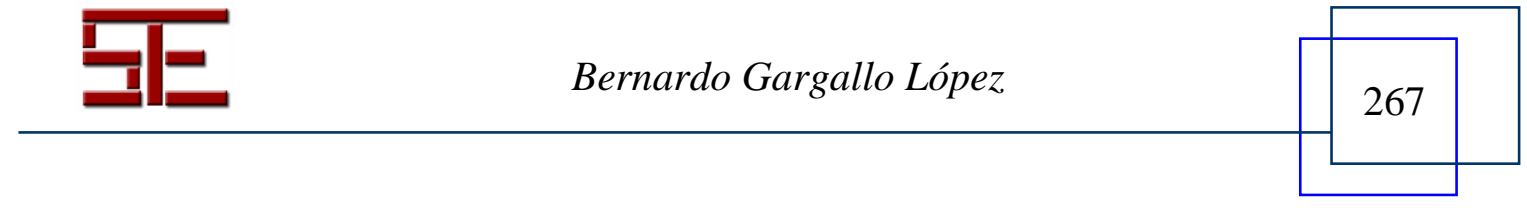




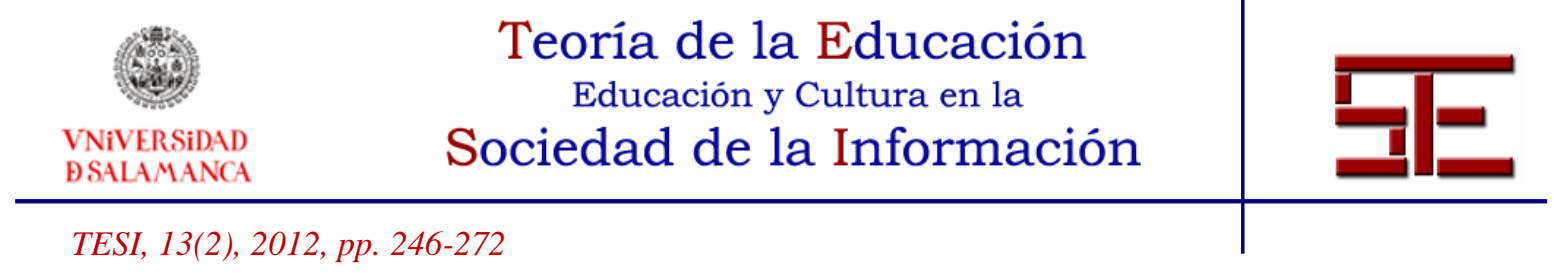

para ser más (recordemos los cuatro pilares de la educación del Informe Delors: "aprender a conocer, aprender a hacer, aprender a ser, aprender a convivir"), para dar más, para vivir mejor y para convivir mejor. El horizonte es el del pleno desarrollo personal y el del compromiso cívico, social y político. Lo que nos permite integrar de nuevo nuestro discurso en el entorno de la autonomía y responsabilidad. Autonomía para ser competente en el manejo de los mecanismos para aprender. Responsabilidad para comprometerse con la propia mejora, con la mejora de los demás y del entorno en que se vive. Aprender a ser y a convivir, no quedándose con el saber y el saber hacer. Lo que nos conduce al mundo de los valores, instrumentales y terminales. Con especial referencia a los valores morales. La educación está firmemente enraizada en los valores, de todo tipo, pero también en los valores morales. La orientación hacia lo bueno es una característica esencial en la educación, que siempre precisa de criterios morales. Una persona educada es la que hace el bien. La vida de las personas se rige por los valores, y tenemos que desarrollar buenos valores.

Hoy en día hay que insistir en ello porque parece que todo vale y por el relativismo moral imperante en mensajes muy presentes en el entorno. Los referentes deben ser personas y personalidades que trabajan, se esfuerzan y se comprometen, que cooperan en la lucha contra la ignorancia, en el desarrollo de la ciencia y la tecnología, en el servicio a los demás, en la defensa de los más débiles, en la lucha por la libertad y la justicia, en la construcción de un mundo mejor.

Y los valores son los que sostienen las actitudes que todos construimos ante la vida y que, si los ponemos en práctica, nos permitirán hacer que este mundo nuestro sea un hogar habitable y digno para todos... Con todo ello aprenderemos a "ser personas" y a "convivir" y a trabajar en proyectos comunes: éste es uno de los retos más importantes del siglo XXI. Debemos aprender a descubrir progresivamente al otro; debemos ver que tenemos diferencias, pero sobre todo tenemos cosas comunes: todo ser humano quiere ser libre, vivir feliz, con dignidad y respeto. Tenemos interdependencias, dependemos los unos de los otros. Y para descubrir al otro, debemos conocernos a nosotros mismos: cuando sepa quién soy yo, sabré plantearme la cuestión de la empatía, entenderé que el otro piense diferente de mí y que tiene razones tan justas como las mías para discrepar.

Por eso es tan importante que se favorezcan los trabajos conjuntos, que se preste atención a lo común, a lo que nos une, que siempre es más que lo que nos separa, pero que también se destaque la diversidad, la diferencia, como elemento necesario y creador. Defendiendo siempre, eso sí, nuestros valores auténticos. Utilizar y aprovechar

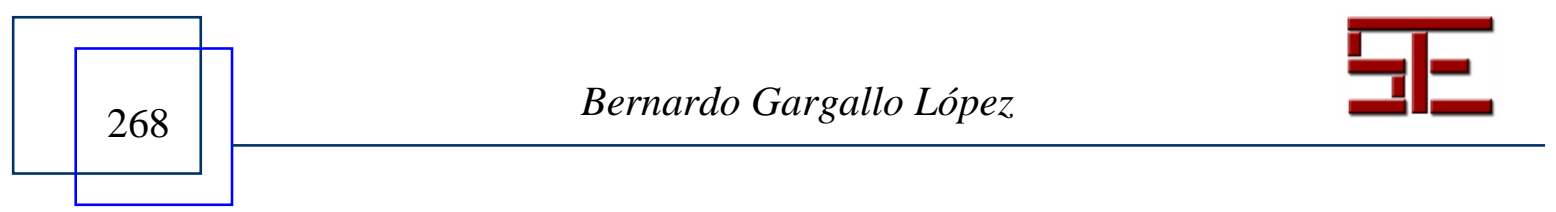




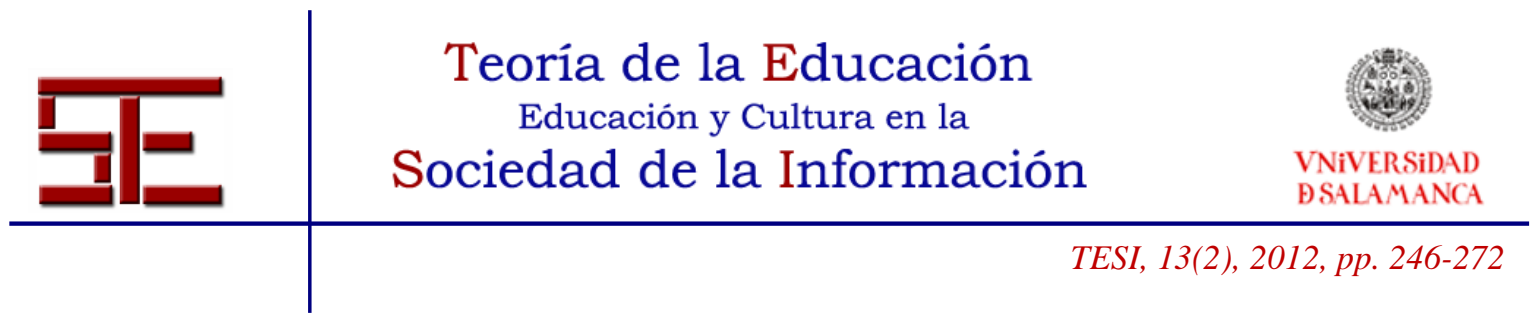

la riqueza de la diversidad, tratarla adecuadamente para igualar las desigualdades, pero respetando las diferencias y así evitar conflictos. La diversidad es un valor. Es una riqueza de que dispone la humanidad, que es la que ha dado diferentes culturas, diferentes costumbres, diferentes religiones, diferentes lenguajes, y también la gran riqueza de obras de arte, literatura, etc.

En último término, son los valores los que están en la base del desarrollo personal y social y de la vida buena para nosotros y para los demás. Son ellos los que dibujan el horizonte al que dirigir nuestros esfuerzos en el aprender a aprender.

\section{5.- BIBLIOGRAFÍA.}

Abascal, J. (2003). El sí mismo en los procesos de enseñanza-aprendizaje. En Mª V. Trianes y J. A. Gallardo (Coords.), Psicología de la educación y del desarrollo (pp. 496-522). Madrid: Pirámide.

Alonso Tapia, J. (1991). Motivación y aprendizaje en el aula. Cómo enseñar a pensar. Madrid: Santillana/Aula XXI.

Ayala, C. L., Martínez, R. y Yuste, C. (2004). CEAM. Cuestionario de estrategias de aprendizaje y motivación. Barcelona: Instituto de Orientación Psicológica EOS.

Beltrán, J. (2003). Estrategias de aprendizaje. Revista de Educación, 332, 55-73.

Beltrán, J., Pérez, L. F. y Ortega, M. I. (2006). CEA. Cuestionario de Estrategias de Aprendizaje. Madrid: TEA.

Bernad, J. A. (1999). Estrategias de aprendizaje. Madrid: Bruño.

Brown, A. L. y Campione, J. C. (1979). Inducing flexible thinking: a problem of metacognition. En R. Glasser (Ed.), Advances in instructional psychology. Hillsdale: N.J. Erlbaum.

Camarero, F., Martín, F. \& Herrero, J. (2000). Estilos y estrategias de aprendizaje en estudiantes universitarios. Psicothema, 12 (4), 615-622.

Cano, F. y Justicia, F. (1993). Factores académicos, estrategias y estilos de aprendizaje. Revista de Psicología General y Aplicada, 46 (1), 89-99.

Corno, L. (1994). Implicit teachings and self-regulated learning. Comunicación presentada en el Annual Meeting of the American Educational Research Association. New Orleans, LA, April, 4-8.

Danserau, D. F. (1985). Learning Strategy Research. En H. F. O’Neil (Ed.), Learning Strategies (pp. 209-240). Nueva York: Academic Press.

De Bono, E. (1986). El pensamiento lateral. Barcelona: Paidós.

Feuerstein, R. (1988). Programa de Enriquecimiento Instrumental. Madrid: Bruño.

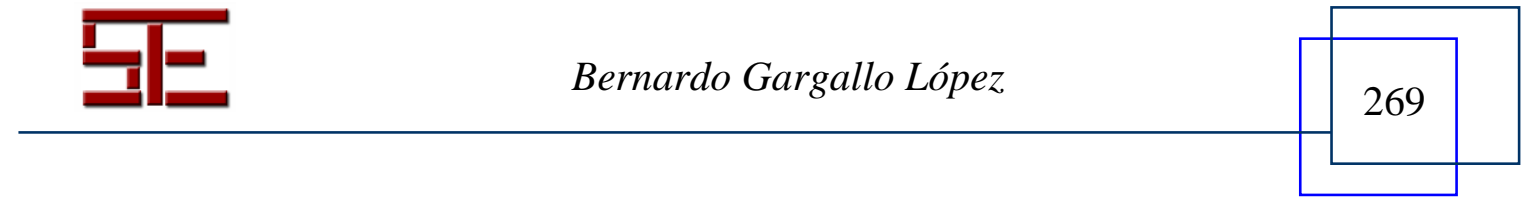




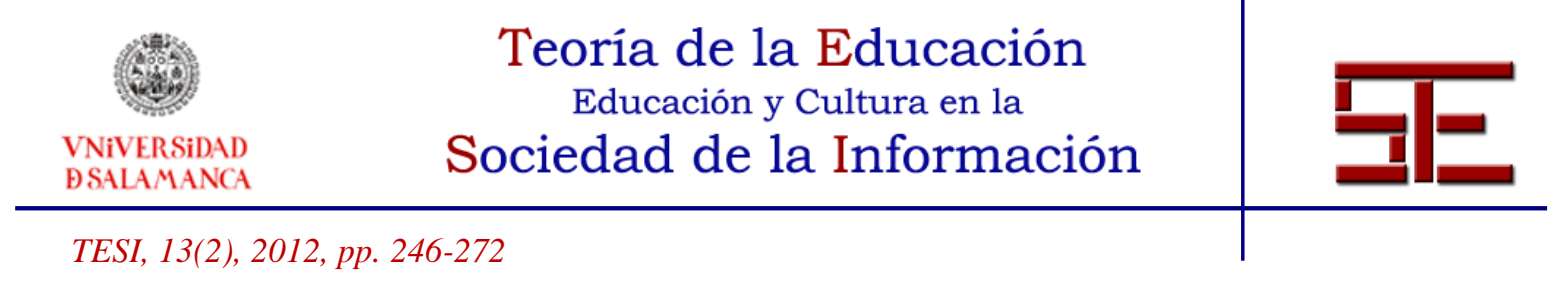

García, T. y Pintrich, P. R. (1991). Student motivation and self-regulated learning. Comunicación presentada en el Annual Meeting of the American Educational Research Association. Chicago, IL, April 3-7.

- (1993). Self-schemas, motivational strategies and self-regulated learning. Comunicación presentada en el Annual Meeting of the American Educational Research Association. Atlanta, GA, April 12-16.

Gargallo, B. (1994). La enseñanza de estrategias de expresión escrita en Educación Secundaria Obligatoria. Un programa de actuación didáctica. Revista de Educación, 305, 353-367.

- (1995). Estrategias de aprendizaje. Estado de la cuestión. Propuestas para la intervención educativa. Teoría de la Educación. Revista Interuniversitaria, 7, 53-75.

- (1997). La enseñanza de estrategias de aprendizaje en el currículum escolar. Un programa de intervención en $6^{\circ}$ de Primaria. Revista de Educación, 312, 227 246.

- (2000). Procedimientos. Estrategias de aprendizaje. Su naturaleza, enseñanza y evaluación. Valencia: Tirant lo Blanch.

- (2006). Estrategias de aprendizaje, rendimiento y otras variables relevantes en estudiantes universitarios. Revista de Psicología General y Aplicada, 59, 109130.

Gargallo, B. y Ferreras, A. (2000). Estrategias de Aprendizaje. Un programa de intervención para ESO y EPA. Primer Premio Nacional de Investigación Educativa 2000. Madrid: MEC/CIDE.

Gargallo, B., Garfella, P. R., Pérez, C. y Fernández, A. (2010). Modelos de enseñanza y aprendizaje en la universidad. Ponencia III. Seminario Interuniversitario de Teoría de la Educación. Madrid: Universidad Complutense (noviembre de 2010). Disponible en http://www.ucm.es/info/site/ucm2010/docu/29site/ ponencia3.pdf

Gargallo, B. y Ruiz, M.A. (1994). Aprender a aprender. Dos procedimientos de enseñanza de estrategias de aprendizaje en resolución de problemas matemáticos en $8^{\circ}$ de EGB. Bordón, 46 (1), 19-34.

Gargallo, B., Suárez, J. y Ferreras, A. (2007). Estrategias de aprendizaje y rendimiento académico en estudiantes universitarios. Revista de Investigación Educativa, 2, 421-441.

Gargallo, B., Suárez-Rodríguez, J. M. y Pérez-Pérez, C. (2009). El cuestionario CEVEAPEU. Un instrumento para la evaluación de las estrategias de

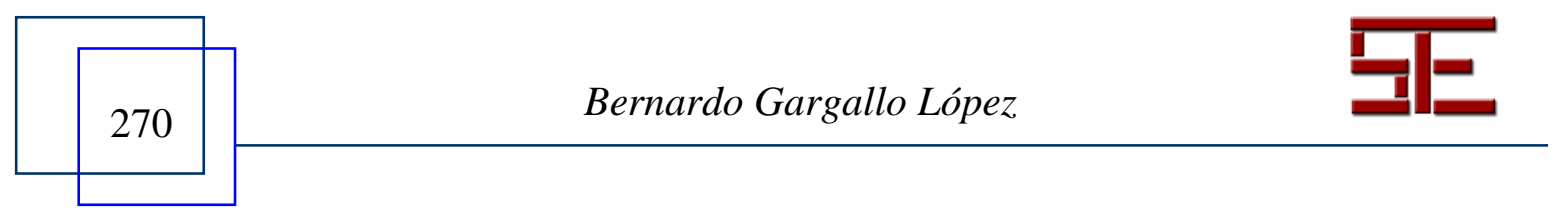




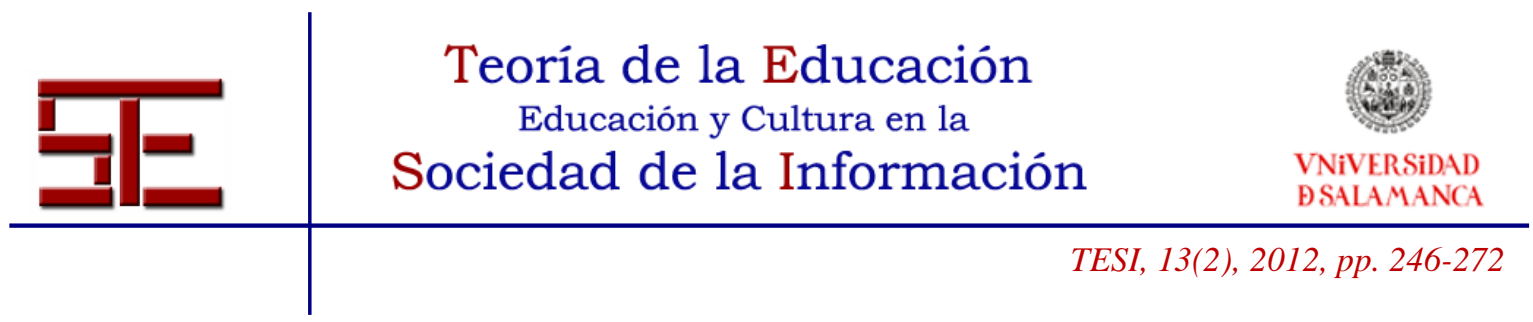

aprendizaje de los estudiantes universitarios. RELIEVE, 15, 2, 1-31. http://www.uv.es/RELIEVE/v15n2/RELIEVEv15n2_5.htm.

Justicia, F. y Cano, F. (1993). Concepto y medida de las estrategias y estilos de aprendizaje. En C. Monereo (Comp.), Las estrategias de aprendizaje: procesos, contenidos e interacción ( pp.113-126). Barcelona: Domènech Ediciones.

Kirby, J. R. (1984). Cognitive strategies and educational performance. Orlando: Academic Press.

Megía, C. (Coord.) (1992). Proyecto de inteligencia "Harvard”. Madrid: Cepe.

Monereo, C. (1994). Estrategias de enseñanza y aprendizaje. Formación del profesorado y aplicación en el aula. Barcelona: Graó.

- (Coord.) (1998). Estratègies d'aprenentatge. Volum I. Assessorament $i$ formació del professorat. Barcelona: Edicions de la Universitat Oberta de Catalunya.

Monereo, C. y Castelló, M. (1997). Las estrategias de aprendizaje. Cómo incorporarlas a la práctica educativa. Barcelona: Edebé.

Nickerson, R. S., Perkins, D. N. y Smith, E. E. (1987). Enseñar a pensar. Aspectos de la aptitud intelectual. Barcelona: Paidós/MEC.

Nisbet, J. (1991). Investigación reciente sobre estrategias de aprendizaje y pensamiento en la enseñanza. En C. Monereo (Comp.), Enseñar a pensar a través del currículum escolar. Barcelona: Casals.

Nisbet, J. y Shucksmith, J. (1987). Estrategias de aprendizaje. Madrid. Santillana.

Norton, L. S. y Crowley, Ch. M. (1995). Can students be helped to learn? An evaluation of an approach to learning programme for first year degree students, Higher Education. 29, 307-328.

Ortiz, L., Salmerón, H. y Rodríguez, S. (2007). La enseñanza de estrategias de aprendizaje en educación infantil. Profesorado. Revista de currículum y formación del profesorado, $11(2), \quad 1-22$. http://www.ugr.es/local/recfpro/rev112COL2.pdf

Pérez Cabaní, Ma . L. (1998). La formació del professorat per a ensenyar estratègies d'aprenentatge. En C. Monereo (Coord.), Estratègies d'aprenentatge. Volum I. Assessorament i formació del professorat. Barcelona: Edicions de la Universitat Oberta de Catalunya.

Pintrich, P. R. (1995). Understanding self-regulated learning. New Directions for Teaching and Learning, 63, 3-12.

Pozo J. I. (1990). Estrategias de aprendizaje. En C. Coll, J. Palacios y A. Marchesi, Desarrollo psicológico y educación, II. Psicología de la educación (pp. 199221). Madrid: Alianza.

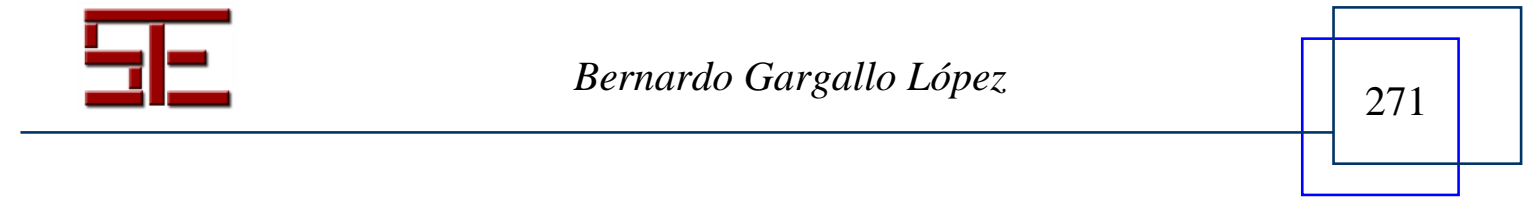




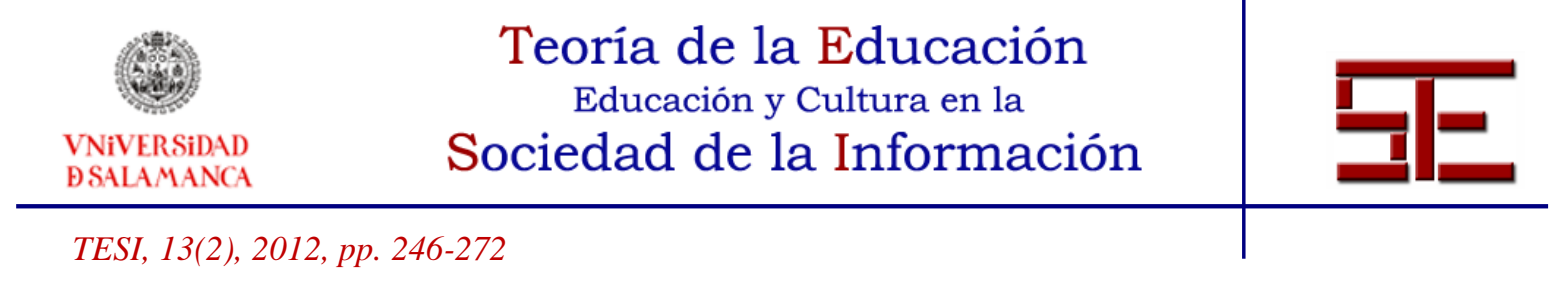

Pozo, J. I. y Monereo, C. (Coords.) (1999). El aprendizaje estratégico. Madrid: Santillana.

Roces, C., Tourón, J. y González, M. C. (1995). Validación preliminar del CEAM II (Cuestionario de estrategias de aprendizaje y motivación II). Psicológica, 16 (3), 347-366.

Román, J. M. y Gallego, S. (1994). ACRA. Escalas de estrategias de aprendizaje. Madrid: TEA.

Rosàrio, M., Mourao, M., Núñez, J. C., González Pienda, J., Solano, P. y Valle, A. (2007). Eficacia de un programa instruccional para la mejora de procesos y estrategias de aprendizaje en la enseñanza superior, Psicothema, 19 (3), 422427.

Tei, E. y Stewart, O. (1985). Effective study from the text: Applying metacognitive strategies. Forum for reading, 16 (2), 46-55.

Tomlinson, L. (1987). Recognition to recall: Self-Questioning to enhance students' metacognition of organization and demands of text. Comunicación presentada en el Annual Meeting of the International Reading Association, 3-7 de mayo de 1987, Anaheim.

Valle, A. y Rodríguez, A. (1998). Estrategias de aprendizaje y rendimiento académico. Boletín de Psicología, 60, 27-53.

Weinstein, C.E. y Danserau, D.F. (1985). Learning strategies: the how of learning. En J. W. Segal et al., Thinking and learning strategies (pp. 125-142). Hillsdale: Erlbaum.

Weinstein, C. E., Husman, J. y Dierking, D. (2002). Self-Regulation Interventions with a focus on learning strategies. En M. Boekaerts, P. R. Pintrich y M. Zeinder; Handbook of Self-regulation (pp. 727-747). San Diego: Academic Press.

Weinstein, C. E., Palmer, D. R. y Schulte, A. C. (1987). LASSI: Learning and Study Strategies Inventory. Clearwater, FL: Publishing Company.

Zimmerman, B. J. (1990). Self-regulated learning and academic achievement: An overview. Educational Psychologist, 25, 3-17.

Zimmerman, B. J. y Martínez-Pons, M. (1988). Construct validation of a model of student self-regulated learning. Journal of Educational Psychology, 80 (3), 284290.

Para citar el presente artículo puede utilizar la siguiente referencia:

Gargallo López, B. (2012). Un aprendiz estratégico para una nueva sociedad. Revista Teoría de la Educación: Educación y Cultura en la Sociedad de la Información. 13(2), 246-272 [Fecha de consulta: dd/mm/aaaa].

http://campus.usal.es/ revistas_trabajo/index.php/revistatesi/article/view/9008/9252

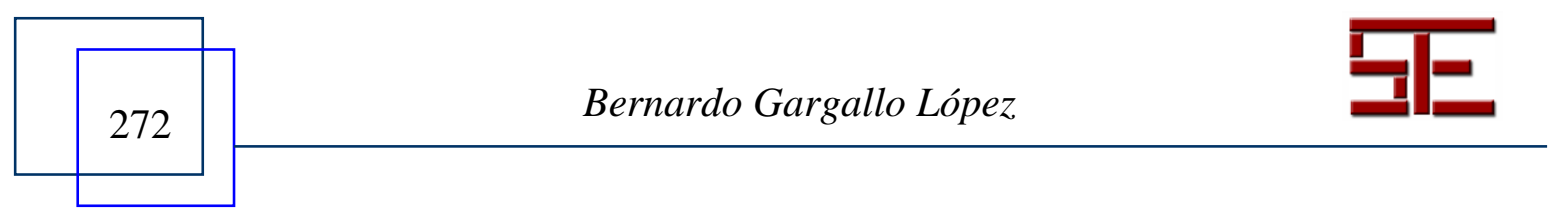

